\title{
Elastic liposomes as novel carriers: recent advances in drug delivery
}

\author{
This article was published in the following Dove Press journal: \\ International Journal of Nanomedicine \\ 17 July 2017 \\ Number of times this article has been viewed
}

\author{
Afzal Hussain ${ }^{1,2}$ \\ Sima Singh' \\ Dinesh Sharma ${ }^{3}$ \\ Thomas J Webster ${ }^{4}$ \\ Kausar Shafaat ${ }^{2}$ \\ Abdul Faruk ${ }^{5}$ \\ 'Department of Pharmaceutical \\ Sciences and Technology, Birla \\ Institute of Technology, Mesra, Ranchi, \\ Jharkhand, India; ${ }^{2}$ Faculty of Pharmacy, \\ Sachchidananda Sinha College, \\ Aurangabad, Bihar, India; ${ }^{3}$ Zifam Pyrex \\ Myanmar Co. Ltd., Yangon, Myanmar; \\ ${ }^{4}$ Department of Chemical Engineering, \\ Northeastern University, Boston, MA, \\ USA; ${ }^{5}$ Department of Pharmaceutical \\ Sciences, Hemwati Nandan Bahuguna \\ Garhwal University, Srinagar, \\ Uttarakhand, India
}

\begin{abstract}
Elastic liposomes (EL) are some of the most versatile deformable vesicular carriers that comprise physiologically biocompatible lipids and surfactants for the delivery of numerous challenging molecules and have marked advantages over other colloidal systems. They have been investigated for a wide range of applications in pharmaceutical technology through topical, transdermal, nasal, and oral routes for efficient and effective drug delivery. Increased drug encapsulation efficiency, enhanced drug permeation and penetration into or across the skin, and ultradeformability have led to widespread interest in ELs to modulate drug release, permeation, and drug action more efficiently than conventional drug-release vehicles. This review provides insights into the versatile role that ELs play in the delivery of numerous drugs and biomolecules by improving drug release, permeation, and penetration across the skin as well as stability. Furthermore, it provides future directions that should ensure the widespread use of ELs across all medical fields.
\end{abstract}

Keywords: elastic liposomes, drug delivery, topical, transdermal, enhanced delivery

\section{Introduction}

Elastic liposomes (ELs) are biocompatible bilayer vesicular systems that can deliver numerous drugs for therapeutic, biochemical, and cosmetic purposes. They are known under different names - deformable liposomes, ultradeformable liposomes, flexible liposomes, ultraflexible liposomes, and transfersomes (pioneered by IDEA AG, Munich, Germany). Such vesicular systems have been developed and reported for topical, nasal, biological (vaccines and toxoids), and transdermal delivery systems comprising hydrophobic and hydrophilic components. ELs can accommodate challenges faced by traditional drug delivery vehicles due to their improved physicochemical and pharmacokinetic properties. ${ }^{1}$

ELs consist of phospholipids, surfactants such as edge activators (EA), and an inner aqueous compartment enclosed within a lipid bilayer capable of encapsulating hydrophilic (in an aqueous chamber) and lipophilic (in a lipid bilayer) molecules. Moreover, materials such as charged lipids (cationic and anionic), polyethylene glycol (PEG; PEGylation), ethanol, cyclodextrin complexes, and gels have been employed. ${ }^{2}$ Its composition influences its physicochemical properties and, subsequently, efficacy by altering skin penetration behavior. It is noteworthy that in vivo skin permeation performance is quite different from in vitro behavior and cannot be justified by in vitro data due to significant differences. ${ }^{3}$ The latter mechanism is widely used to determine the permeation behavior of ELs due to convenience. ${ }^{4}$ However, comprehensive studies are still needed on ELs to glean sufficient in vivo data. In the present review, studies on the use of ELs to deliver drugs for treating different diseases are summarized.
Correspondence: Thomas J Webster Department of Chemical Engineering, Northeastern University, 360 Huntington Avenue, Boston, MA 02115, USA

Tel + I 6173736585

Email th.webster@neu.edu
International Journal of Nanomedicine 2017:12 5087-5108 Dovepress f $y$ in 0 http://dx.doi.org/1 $0.2147 /$ IJN.SI 38267 (c) (1) (-) 2017 Hussain et al. This work is published and licensed by Dove Medical Press Limited. The full terms of this license are available at https://www.dovepress.com/terms.php cc) ${ }_{\mathrm{BY}} \mathrm{NC}$ and incorporate the Creative Commons Attribution - Non Commercial (unported, v3.0) License (http://creativecommons.org/licenses/by-nc/3.0/). By accessing the work you hereby accept the Terms. Non-commercial uses of the work are permitted without any further permission from Dove Medical Press Limited, provided the work is properly attributed. For permission for commercial use of this work, please see paragraphs 4.2 and 5 of our Terms (https://www.dovepress.com/terms.php). 
In 1992, Cevc and Blume were first credited with the introduction of this novel alternative to conventional liposomes to facilitate drug passage across the stratum corneum (SC) of skin. ${ }^{5}$ ELs are colloidal lipid nanocarriers composed of unique components with characteristic ultradeformability and elasticity to squeeze across microlamellar spaces (which are $1 / 10$ th the vesicle diameter) among keratinocytes to pass intact across the skin layer and increase skin hydration to improve transepidermal water loss (TEWL). ${ }^{6}$ Presently, the enhanced permeability of ELs is generally significant enough due to synergistic effects of ELs acting as a carrier and penetrant. However, results from recent studies have suggested that the former mechanism is more prominent than the latter. ${ }^{7}$ Impressively, EL vesicles can penetrate the skin without disintegration. ${ }^{8}$

This review compiles significant informative data on the application of ELs for nasal, brain, and oral deliveries. ELs offered an alternative substitute for the delivery of hydrophilic, lipophilic, thermolabile (eg, protein and peptides), and $\mathrm{pH}$-sensitive molecules (enzymes) or chemical-sensitive candidates, toxoids, nucleic acids, and vaccines with significant desirable outcomes. ${ }^{9-13}$ Thus, the review is of great value for researchers and scientists working on improving drug delivery across the skin through the use of ELs.

\section{ELs as a drug delivery system}

In recent decades, various active pharmaceutical ingredients (API), such as thermolabile proteins, acid-labile drugs, enzyme-susceptible, highly lipophilic, hydrophilic, photosensitive drugs, and high-molecular-weight molecules, have been encapsulated within ELs. ${ }^{7,12,13}$ Extensive literature reviews have reported significantly increased interest in exploring ELs as a new approach to improve drug therapeutic efficacy across diverse applications. Biocompatible ELs are an effective and efficient strategy for drug delivery, with considerable interest from formulation scientists. Furthermore, a wide range of available lipids, surfactants (activators), and other components (eg, alcohols in trace amounts) have been used for developing ELs, making the system highly suitable for various applications. A typical structure of an EL with essential components is depicted in Figure 1.

Recently, new ELs have been exploited for topical delivery (TD) of numerous drugs due to several inherent advantages and features. ${ }^{14}$ For example, formulation scientists have sparked substantial interest to employ novel ELs as more efficient delivery vehicles by targeting them to a target site at low dose and cost.

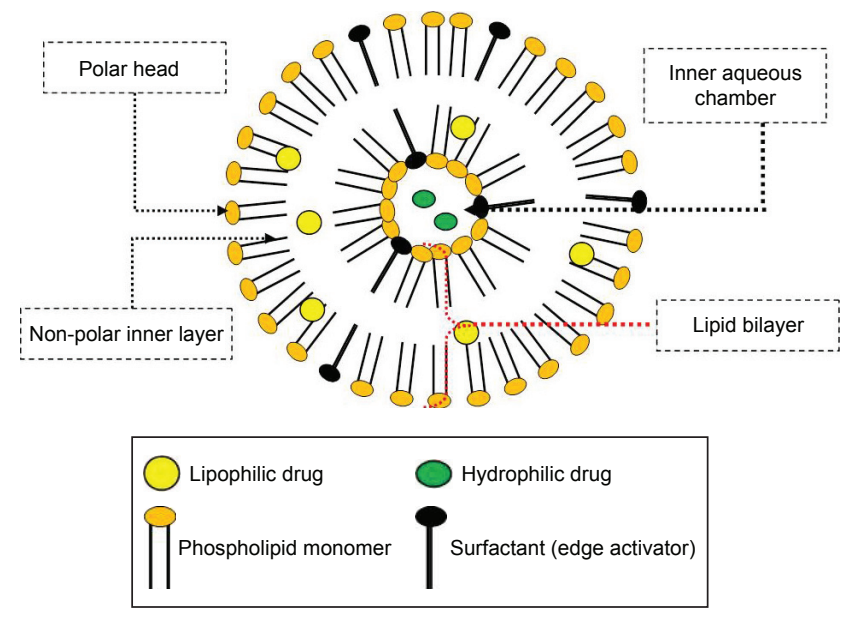

Figure I Schematic illustration of bilayer elastic liposomes displaying various components and structural morphology.

\section{Composition and methods of preparation}

Amphipathic phospholipids with various chemical structures, EA, and aqueous compartments are major components of ELs. EA - which reduces the transition temperature and destabilizes the lipid bilayer of ELs for increased fluidity determines the permeation behavior of ELs through the skin. A thorough understanding of various EAs is a prerequisite for the screening of an ideal EA. ${ }^{15}$ Drug delivery can be modulated by changing the type and concentration of each component. ${ }^{15}$ The most preferred phospholipids are unsaturated soya phosphatidylcholine (PC) and egg PC ( 10\% w/w). In general, lipids have low transition temperatures. These are in a liquid crystal state at high temperatures, and this causes drug leakage (due to increased permeability of the trapped drug) at room temperature $\left(25^{\circ} \mathrm{C}\right)$ and when applied onto the skin $\left(32^{\circ} \mathrm{C}\right)$. Therefore, its transition temperature $\left(\mathrm{T}_{\mathrm{m}}\right)$ should be set at a temperature between these temperatures for prolonged storage stability by modulating the lipid bilayer architecture. Amphipathic molecules containing a glycerol bridge link a pair of hydrophobic acyl hydrocarbon chains with a polar hydrophilic head, thereby affecting the phase transition of the lipid membrane for enhanced elasticity. ${ }^{7}$ Detailed roles of the lipid and EA are summarized in Table 1.,16-18 Several EA are presented in Table 2, together with their important physicochemical properties that need to be considered before EL fabrication. ${ }^{19-26}$ Such systems enable delivery of numerous challenging molecules at high concentrations into and through the skin by topical and transdermal applications, respectively. The ratio of lipid to EA should be optimal for better elasticity and stability in order to achieve an efficient permeation potential and long-term storage stability, respectively. Other components could be PEG-400-grafted lipids, 
Table I Characteristic features of lipids and their effects on vesicle performance

\begin{tabular}{|c|c|c|c|c|c|}
\hline \multirow[t]{2}{*}{ Name } & \multicolumn{5}{|c|}{ Basic profile of lipids essential for the development of vesicular systems } \\
\hline & Molecular weight & Molecular formula & Degree of unsaturation & Charge & $\mathbf{T}_{\mathrm{m}}$ \\
\hline L- $\alpha$ phosphotidylcholine (PC) & 313.24 & $\left(\mathrm{C}_{10} \mathrm{H}_{20} \mathrm{NO}_{8} \mathrm{P}\right)$ & Saturated & Neutral & $<0^{\circ} \mathrm{C}$ \\
\hline Hydrogenated soy (HSPC) & 783.77 & $\left(\mathrm{C}_{44} \mathrm{H}_{88} \mathrm{NO}_{8} \mathrm{P}\right)$ & Saturated & Neutral & $<0^{\circ} \mathrm{C}$ \\
\hline Phosphotidylserine (PS) & 385.304 & $\left(\mathrm{C}_{13} \mathrm{H}_{24} \mathrm{NO}_{10} \mathrm{P}\right)$ & Saturated & Neutral & $<0^{\circ} \mathrm{C}$ \\
\hline Phosphotidylinositol (PI) & 886.56 & $\left(\mathrm{C}_{47} \mathrm{H}_{83} \mathrm{O}_{13} \mathrm{P}\right)$ & Unsaturated & Anionic & $<0^{\circ} \mathrm{C}$ \\
\hline $\begin{array}{l}\text { I,2-dioleoyl-3-trimethyl ammonium } \\
\text { propane (DOTAP) }\end{array}$ & 698.55 & $\left(\mathrm{C}_{42} \mathrm{H}_{80} \mathrm{CINO}_{4}\right)$ & Unsaturated & Cationic & $<5^{\circ} \mathrm{C}$ \\
\hline $\begin{array}{l}\text { I,2-dioleoyl-sn-glycero-3-phosphate } \\
\text { (DOPA) }\end{array}$ & 722.95 & $\left(\mathrm{C}_{39} \mathrm{H}_{72} \mathrm{O}_{8} \mathrm{PNa}\right)$ & Unsaturated & Cationic & $-2^{\circ} \mathrm{C}$ \\
\hline I,2-dipalmitoyl-sn-glycero-PC (DGPC) & 734.1 & $\left(\mathrm{C}_{40} \mathrm{H}_{80} \mathrm{NO}_{8} \mathrm{P}\right)$ & Saturated & Neutral & $41^{\circ} \mathrm{C}$ \\
\hline DL- $\alpha$ PC (DPC) & 790.15 & $\left(\mathrm{C}_{44} \mathrm{H}_{89} \mathrm{NO}_{8} \mathrm{P}\right)$ & Saturated & Cationic & \\
\hline $\begin{array}{l}\text { I,2-dilauroyl-sn-glycero-3- } \\
\text { phosphocholine (DLPC) }\end{array}$ & 621.437 & $\left(\mathrm{C}_{32} \mathrm{H}_{64} \mathrm{NO}_{8} \mathrm{P}\right)$ & Unsaturated & Cationic & $-2^{\circ} \mathrm{C}$ \\
\hline $\begin{array}{l}\text { I,2-dioleoyl-sn-glycero-3- } \\
\text { phosphocholine (DOPC) }\end{array}$ & 786.59 & $\left(\mathrm{C}_{44} \mathrm{H}_{84} \mathrm{NO}_{8} \mathrm{P}\right)$ & Unsaturated & Cationic & $-17^{\circ} \mathrm{C}$ \\
\hline
\end{tabular}

\begin{tabular}{|c|c|}
\hline Lipid properties & Significant role \\
\hline I. Chain length and degree of saturation & $\begin{array}{l}\text { ELs are mainly composed of unsaturated PC with a low transition temperature. }{ }^{7} \mathrm{DLPC}(\mathrm{C}: \mathrm{I} \text { )-based } \\
\text { EL showed more elastic and enhanced transdermal flux (fourfold higher than drug solution) of } \\
\text { sumatriptan than vesicles composed of DOPC (C:I8). }{ }^{16}\end{array}$ \\
\hline 2. Lipid purity & $\begin{array}{l}\text { The purity of PC possibly affected the permeation behavior of vesicles as studied with different } \\
\text { concentrations: } 95 \%, 78.6 \% \text {, and } 50 \% \text { of PC. The best result was obtained with } 95 \% \text { pure PC. }{ }^{17}\end{array}$ \\
\hline 3. Lipid composition & $\begin{array}{l}\text { The use of unsaturated } \mathrm{PC} \text { with lower } \mathrm{T}_{\mathrm{m}} \text { value results in high membrane flexibility. Moreover, EL } \\
\text { suffered irreversible aggregation when rehydrated with freeze-dried ELs, even at high sugar-to-lipid- } \\
\text { mass ratios }(4: 1) \text { used as a cryoprotectant. }\end{array}$ \\
\hline 4. Transition temperature $\left(\mathrm{T}_{\mathrm{m}}\right)$ & $\begin{array}{l}\text { The liquid crystal state of the lipids contributes to the increased permeability of the encapsulated } \\
\text { drug at room temperature }\left(25^{\circ} \mathrm{C}\right) \text {. Therefore, more attention should be paid to stabilize the vesicle } \\
\text { during long-term stability. The } \mathrm{T}_{\mathrm{m}} \text { of EL vesicles can be easily modified by changing the ratio of PC in } \\
\text { the liposome bilayer to set the } \mathrm{T}_{\mathrm{m}} \text { between the storage temperature and skin temperature }\left(32^{\circ} \mathrm{C}\right) \text {, } \\
\text { such as at } 30^{\circ} \mathrm{C} \text {. Moreover, after application to the skin, the vesicle turns into a liquid state owing } \\
\text { to skin temperature }\left(32^{\circ} \mathrm{C}\right) \text { being greater than its } \mathrm{T}_{\mathrm{m}} \text {, which subsequently provides higher elasticity. }\end{array}$ \\
\hline
\end{tabular}

Abbreviations: C:12, unsaturation at carbon number 12; C:18, unsaturation at carbon number 18; EL, elastic liposome.

cationic lipids, drug-encapsulating complexing agents such as cyclodextrine, ethyl alcohol (10\% of aqueous volume), and gels as carriers for vesicle formulation. ${ }^{7}$

ELs are commonly prepared by a thin-film formation method using a rotary evaporation technique. ${ }^{15}$ Initially, phospholipids, lipophilic drugs (or hydrophilic drugs in a hydration medium), and surfactants are dissolved in an organic solvent (chloroform or ethanol) at room temperature to obtain a single-phase solution of the excipient in a round bottom flask (RBF) as shown in Figure 2. A complete schematic presentation showing the sequential steps involved in EL preparation of 5-fluorouracil (5-FU) is shown in Figure $2 .{ }^{15}$ The obtained mixture is subjected to a rotary evaporator to form a thin film of the lipid on the inner wall of the RBF that could be redispersed within an aqueous or buffer solution to achieve a milky colloidal suspension of large-sized vesicles. This is further transformed into smaller size unilamellar vesicles (SUV) using an ultra-probe sonicator (Figure 2). The turbid SUV-containing suspension can be lyophilized to increase its stability and packed for dispensing. Figure 3A shows a scanning electron microscopy (SEM) image of lyophilized 5-FU-EL; the transmission electron microscopy (TEM) image revealed an intact flexible vesicle (Figure 3B).

\section{Mechanism of permeation and penetration across the skin}

Skin is the most prominent first-line barrier for numerous drugs after topical application. Several efforts have suggested successful delivery into or across the skin by employing ELs, with or without physical methods. Topically applied EL suspensions interact with the skin, displaying several sequential events. ${ }^{7}$ Initially, water present in the suspension evaporates immediately and increases the concentration of non-volatile excipients on the skin. The hydration gradients along the skin to EL vesicles are well established after reaching the saturation level. Thus, water content increases $(10 \%-30 \%)$ in the upper layer as compared to the inner viable epidermis $(75 \%) .{ }^{3}$ This difference in water content develops transepidermal hydration gradients. Thus, this 
Table 2 Several edge activators and their physicochemical properties

\begin{tabular}{|c|c|c|c|c|c|}
\hline Edge activator & HLB** value & Molecular weight & Molecular formula & CMC* value & Category \\
\hline Tween 80 & $14-15$ & $1,310.0$ & $\mathrm{C}_{64} \mathrm{H}_{124} \mathrm{O}_{26}$ & $13-15 \mathrm{mg} / \mathrm{L}$ & Non-ionic \\
\hline Tween 20 & 16.7 & $1,227.5$ & $\mathrm{C}_{58} \mathrm{H}_{114} \mathrm{O}_{26}$ & $60 \mathrm{mg} / \mathrm{L}$ & Non-ionic \\
\hline Tween 40 & 15.6 & $\mathrm{I}, 283.65$ & $\mathrm{C}_{62} \mathrm{H}_{122} \mathrm{O}_{26}$ & $27 \mathrm{mg} / \mathrm{L}$ & Non-ionic \\
\hline Tween 60 & 14.9 & I,3। I.7 & $\mathrm{C}_{64} \mathrm{H}_{126} \mathrm{O}_{26}$ & $27 \mathrm{mg} / \mathrm{L}$ & Non-ionic \\
\hline Tween 85 & 1.8 & $\mathrm{I}, 838.56$ & $\mathrm{C}_{100} \mathrm{H}_{188} \mathrm{O}_{28}$ & - & Non-ionic \\
\hline Span 80 & 4.3 & 428.6 & $\mathrm{C}_{24} \mathrm{H}_{44} \mathrm{O}_{6}$ & $0.016-0.019 \mathrm{mM}$ & Non-ionic \\
\hline Span 20 & 8.6 & 346.47 & $\mathrm{C}_{18} \mathrm{H}_{34} \mathrm{O}_{6}$ & - & Non-ionic \\
\hline Span 40 & 6.7 & 402.57 & $\mathrm{C}_{22} \mathrm{H}_{42} \mathrm{O}_{6}$ & - & Non-ionic \\
\hline Span 60 & 4.7 & 430.6 & $\mathrm{C}_{24} \mathrm{H}_{46} \mathrm{O}_{6}$ & - & Non-ionic \\
\hline Span 85 & 1.8 & 957.51 & $\mathrm{C}_{60}^{24} \mathrm{H}_{108} \mathrm{O}_{8}$ & - & Non-ionic \\
\hline Sodium cholate & 16.7 & 430.55 & $\mathrm{C}_{24} \mathrm{H}_{39} \mathrm{O}_{5} \mathrm{Na}$ & - & Cationic \\
\hline Sodium deoxycholate & 16 & 414.55 & $\mathrm{C}_{24} \mathrm{H}_{40} \mathrm{O}_{4}$ & $2-6 \mathrm{mM}$ & Cationic \\
\hline Oleic acid & I & 282.46 & $\mathrm{C}_{18} \mathrm{H}_{34} \mathrm{O}_{2}$ & $13-15 \mathrm{mM}$ & Anionic \\
\hline Properties & \multicolumn{5}{|l|}{ Significant role } \\
\hline I. $T_{m}$ & \multicolumn{5}{|c|}{$\begin{array}{l}\text { Addition of EA reduced the } T_{m} \text { value and induced the fluidization of the lipid bilayer. Furthermore, the penetration enhancer } \\
\text { oleic acid was used as a substitute of EA with an additional property of enhancing the effect despite fluidization. }{ }^{19,20}\end{array}$} \\
\hline 2. Concentration & \multicolumn{5}{|c|}{$\begin{array}{l}\text { Micelles are smaller vesicle with reduced entrapment efficiency, limited permeability, poor flexibility, and low sensitivity to } \\
\text { water activity gradients of the skin. } .^{21-24}\end{array}$} \\
\hline $\begin{array}{l}\text { 3. Non-bulky } \\
\text { hydrocarbon chain }\end{array}$ & \multicolumn{5}{|c|}{$\begin{array}{l}\text { Tween } 80 \text { was found to be superior than other Span and bile salt surfactants in terms of permeation flux in transdermal } \\
\text { delivery of diclofenac sodium, which was attributed to non-bulky hydrocarbon chains in Tween } 80 . .^{25}\end{array}$} \\
\hline 4. Elasticity & \multicolumn{5}{|c|}{$\begin{array}{l}\text { The drug leakage increases with increased elasticity. Tween } 80 \text { formed vesicles of higher elasticity than Span } 85 \text { which showed } \\
\text { low drug retention }(48.01 \%) \text { as compared to Span } 84 \text { after } 90 \text { days of storage at lower temperatures }\left(0^{\circ} \mathrm{C} \text { and } 4^{\circ} \mathrm{C}\right) .{ }^{25}\end{array}$} \\
\hline 5. Affinity for lipid & \multicolumn{5}{|c|}{$\begin{array}{l}\text { Lipophilic EA has greater affinity with lipid bilayers which results in increased drug entrapment of lipophilic drug } \\
\text { (griseofulvin). }{ }^{26}\end{array}$} \\
\hline 6. HLB** value & \multicolumn{5}{|c|}{$\begin{array}{l}\text { EA with low HLB values resulted in smaller vesicles and the relationship has been attributed to decreased surface energy } \\
\text { with increases in hydrophobicity. }{ }^{25}\end{array}$} \\
\hline
\end{tabular}

Notes: *Minimum concentration of surfactant at which micelle formation takes place; **hydrophilic lipophilic balance of a surfactant.

Abbreviations: $E A$, edge activators; $T_{m}$, transition temperature.

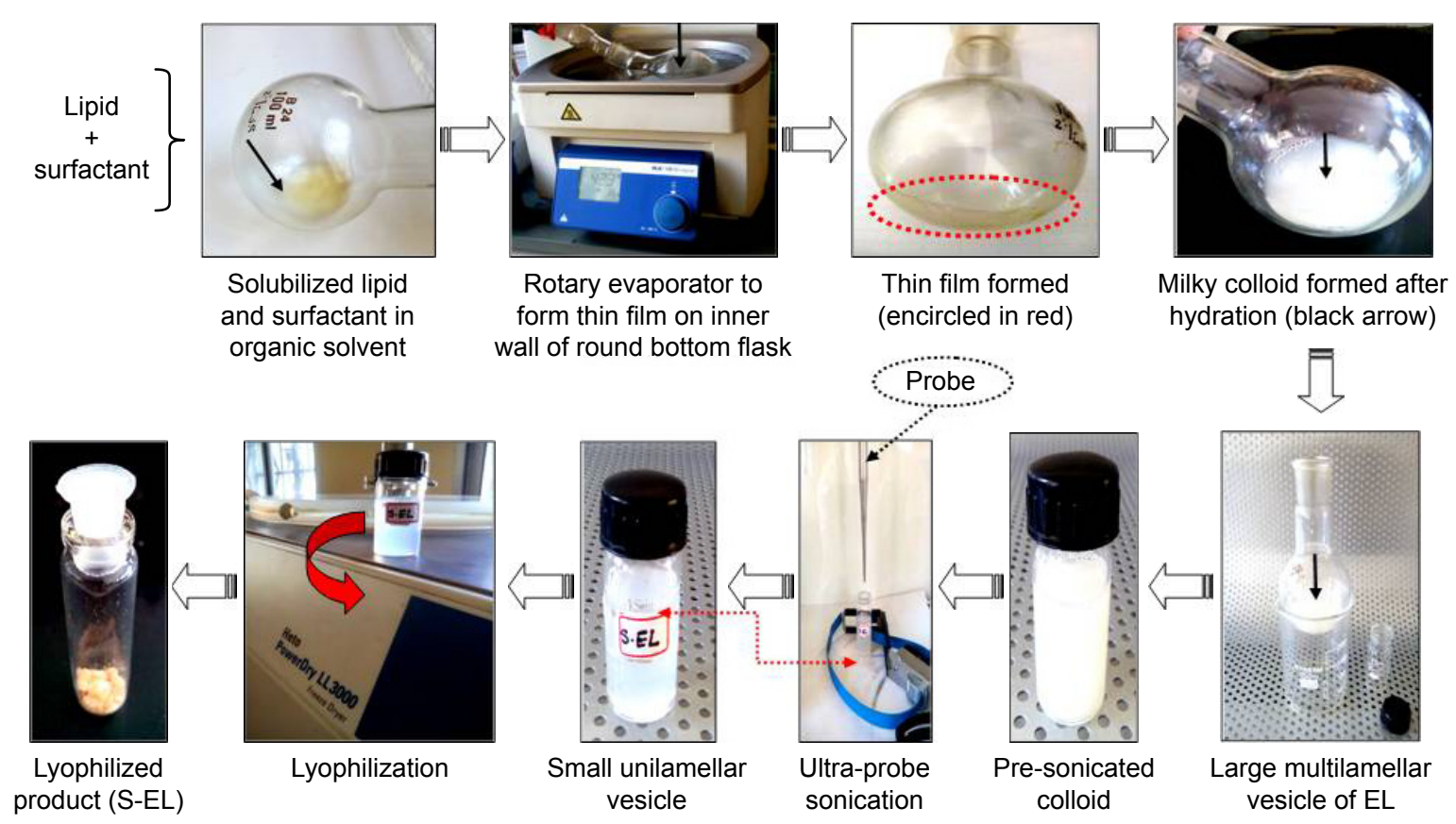

Figure 2 Schematic presentation of sequentially involved steps in the elastic liposome preparation of 5-fluorouracil.

Abbreviations: EL, elastic liposome; S-EL, solidified elastic liposome. 

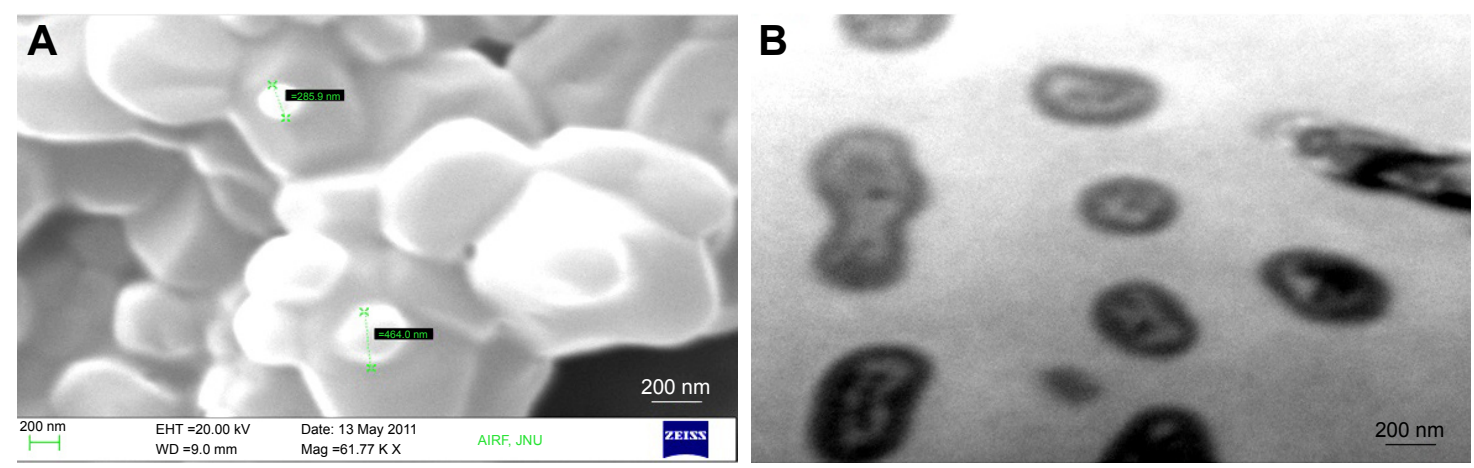

Figure 3 (A) Scanning electron microscopy and (B) transmission electron microscopy of elastic liposomes.

gradient, water affinity of the vesicle, and high elasticity all drive (or "pull") the vesicle toward the inner layer of the skin until it has reached the water-rich viable epidermis. The "pull" mechanism is replaced with a "push" mechanism on the liposomal vesicle after it has crossed the SC barrier by diffusion-mediated mechanisms. Intercellular fluid motion in living skin may also be effective. It is noteworthy that ELs without a transepidermal hydration gradient cannot penetrate the SC layer. Moreover, it cannot be applied occlusively because this may decrease the hydration gradient. ${ }^{3}$

Vesicular systems have been reported in the topical and transdermal delivery of drugs posing delivery challenges. The unique structure of the skin layer is often depicted as the so-called "brick and mortar" pattern, which additionally makes the $\mathrm{SC} \sim 1,000$-fold more poorly permeable as compared to other biological membranes. ${ }^{7} \mathrm{SC}$ is a well-known effective barrier to prevent the entry of foreign materials into the body. Structurally, the SC has a "brick and mortar" pattern, where the corneocytes of hydrated keratin (brick) and the flattened keratinocytes (mononucleated) are interspersed in the intercellular matrix of non-polar lipids (mortar). ${ }^{7}$ Several neighbor corneocyte columns (3-10) are organized to form a cluster in the SC. It is important to note that two different hydrophilic pathways, such as the inter-cluster route (low penetration resistance) and the intercorneocyte pathways, exist in the SC layer. The latter constitutes $>80 \%$ of the pathways between the corneocytes in a tortuous pattern. The SC, viable epidermis, viable thick dermis, and subcutaneous fat tissue are sequentially organized. The dermis is the thickest layer (5-20 times thicker than the epidermis) enriched with blood vessels, lymph vessels, and nerves, and has abundant collagen fibers. The dermis continues with subsequent cutaneous fatty tissue, primarily composed of adipocytes that are further linked with collagen fibers. The ultradeformability and elasticity of ELs allow them to pass intact across the skin, increase skin hydration, and improve TEWL. ${ }^{6,27}$ In the last decade, reports have indicated an increased interest to explore new techniques for enhanced drug permeation into or across the skin. One of them - an efficient delivery method based on vesicles - has evoked considerable interest. ${ }^{8}$ Recently, it has become evident that conventional liposomes are of little or no value as carriers for transdermal delivery. They generally accumulate in the SC (the upper portion), with minimal penetration into the deeper regions or systemic circulation. ${ }^{28}$ Figure 4 illustrates possible mechanisms of vesicular permeation across the skin.

It is noteworthy that the addition of EA in the EL vesicle results in deformability to penetrate across the dense SC layer, which contains very small "pores" relative to the vesicle diameter. The SC layer is composed of 15-20 layers with a thickness of 10-15 $\mu \mathrm{m}$ (dry skin) that serves as rate-limiting barrier in transdermal delivery. ${ }^{29}$ Its thickness reaches to $40 \mu \mathrm{m}$ when swollen on hydration..$^{30}$ Researchers have reported that "pores" in the SC barrier are at least 10 times smaller (1/10th of vesicles) than the ultradeformable vesicle diameter (which generally exceeds $100 \mathrm{~nm}$ ). Moreover, the largest pores on the skin surface are provided by hair follicles and sweat ducts that play insignificant roles in liposomal

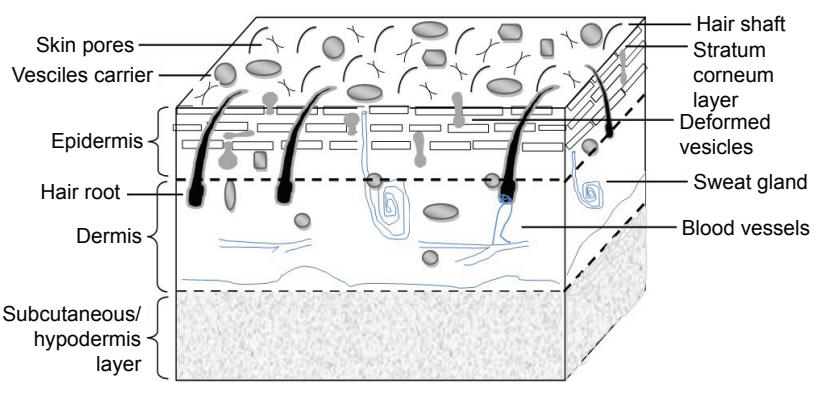

Figure 4 Schematic illustration of permeation mechanisms across the skin. Squeezing and deformability of vesicles through microscopic spaces results in their permeation and penetration. 
transdermal drug penetration. The size obtained from electron microscopy suggests that liposomes up to $600 \mathrm{~nm}$ in diameter can penetrate through the skin, whereas sizes $\geq 1,000 \mathrm{~nm}$ remain in the $\mathrm{SC}{ }^{8}$ Thus, the preferred size range of vesicles for topical/transdermal delivery should be $100-1,000 \mathrm{~nm} \cdot{ }^{29}$

Abd et al reviewed several in vitro and in vivo models for topical drug delivery and stated advantages and certain limitations. The A375 cell line (a metastatic melanoma cultured cell line) is commonly used as a skin cancer model. In brief, ex vivo and in vivo models were classified as 1) human skin: in vivo and ex vivo models are considered the gold standard and the best surrogate for human skin; 2) animal skin (rodent, pig, guinea pig, snake): in vivo, in vivo chimeric skin, and ex vivo skin models are relatively easy to use, but with considerable technical constraints such as difficulty in animal handling and structurally different barrier properties; 3) artificial membranes: these include simple polymeric models and lipid-based models to study diffusion mechanisms and screening purposes, respectively; 4) reconstructed skin models: reconstructed human epidermis serves as a more permeable barrier than human skin; and 5) living skin equivalents: which can be engineered for various skin features. ${ }^{31}$

\section{TD of various drugs}

\section{Topical elastic liposome: advantages and challenges}

Numerous reports have claimed to deliver challenging molecules for TD to the skin with promising advantages, such as direct accessibility of the drugs to the target sites, painless administration to avoid patient noncompliance, free from systemic toxicity as compared to commercially available products, lower drug-plasma fluctuation, localized site-specific drug delivery, bypassing the hepatic metabolism, and noninvasive delivery. ${ }^{32}$ In addition to these distinct advantages, the carrier is of great interest to formulation scientists and research groups for the successful delivery of drugs owing to obvious advantages inherent in the carrier and ease of therapy termination.

Despite promising advantages of $\mathrm{TD}$, there remain some challenges for researchers engaged in EL formulation development. The SC - the outermost layer and interface with the outside world - is considered a major hydrophobic crystalline barrier to TD. Thus, it is even more of a hurdle to deliver hydrophilic and high-molecular-weight complex molecules to the inner strata of the skin. ${ }^{33,34}$ Moreover, the storage stability of ELs poses a challenge. These two challenges need to be addressed technically in the near future.
Several drugs and API belonging to different therapeutic categories have been delivered by exploiting ELs as vesicular carriers intended for TD, as discussed further.

\section{Anticancer drugs}

Skin and breast cancers are extremely serious health issues with increased incidence, by 5\%-10\% annually. ${ }^{15}$ Recent advances have reported the activation of tumor-suppressing transcriptional factors using thymidine dinucleotide-an oligonucleotide. A confocal laser scanning microscopy (CLSM) study revealed enhanced permeation of this factor into the skin. ${ }^{35}$ Paclitaxel and 5-FU need to be readdressed using novel carriers. ${ }^{15,27}$ High dose, short plasma half-lives, and the toxicity of 5-FU in conventional oral/parenteral dosage form a basis for TD. ${ }^{15}$ This study characterized the development of 5-FU-doped ELs for enhanced permeation, by employing various surfactants (Tween 80, Span 80, and Span 60) followed by an in vivo dermal toxicity evaluation. ELs containing Span 80 (EL3-S80) were the most optimal, based on parameters such as particle size $(204 \pm 14.8 \mathrm{~nm})$, zeta potential $(-11.2 \pm 0.2 \mathrm{mV}), \%$ entrapment efficiency (EE) $(88.7 \% \pm 2.9 \%$ ), elasticity (47.7), drug deposition

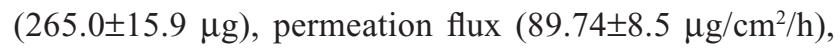
spreadability (101\% $18.9 \%)$, and viscosity $(3,363 \pm 8.23 \mathrm{cp})$. SEM and TEM studies demonstrated the apparently spherical morphology of lyophilized EL3-S80 as shown in Figure 3A and $\mathrm{B}$, respectively. Comparative permeation flux ( $\left.J_{S S}\right)$ studies (Figure 5) revealed an enhanced permeation flux of a Span 80 formulation based on optimized EL3-S80 among the formulations tested, which were 10.03-, 2.45-, and 1.77-fold higher than the drug solution (DS), liposome, and commercial cream, respectively. Enhancement and extraction ratios showed relatively higher values when using EL3-S80 due to

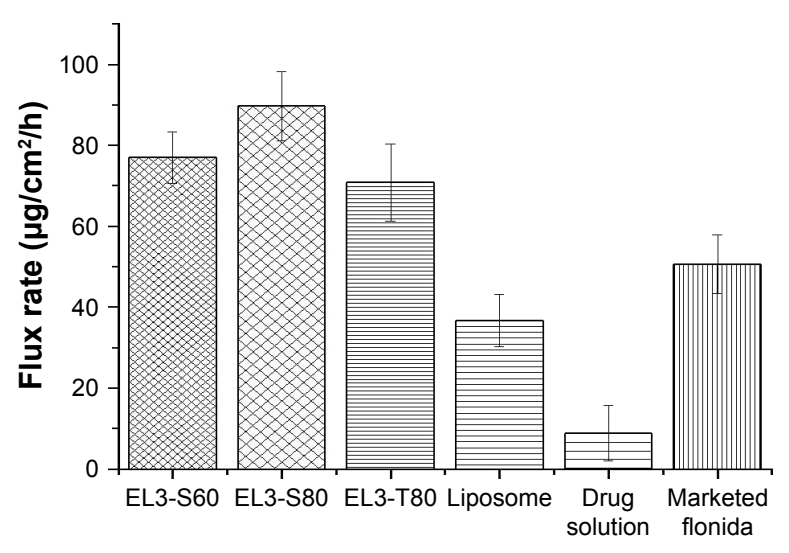

Figure 5 Permeation flux rate of 5-fluorouracil-loaded elastic liposomes prepared from different edge activators as compared to conventional liposomes, marketed flonida, and drug solution across the skin in rats. 
a lower hydrophilic-lipophilic balance (HLB) value of Span 80 , responsible to extract skin lipids associated with the SC barrier. In order to corroborate improved ex vivo skin permeation, Hussain et al supported their findings by performing penetration studies using CLSM with a dye-probed EL3-S80 by visualizing the treated skin. Moreover, safety issues have been studied by performing hemolysis and histopathological assessment. ${ }^{15}$

Furthermore, appropriate surfactant and PC contents were used to fabricate 5-FU-loaded ELs for TD, optimized using Design Expert ${ }^{\circledR}$ (an experimental design program). ${ }^{36}$ EL3-S80 showed maximum permeation flux and \% EE at set responses. Both 3D and 2D contour plots along with predicted and actual graphs (flux and \% EE) are shown in Figure 6. The flux response showed a linear behavior on increasing the PC and Span 80 contents (Figure 6A-C). Similarly, the pattern of \% EE was linear with an increase in PC and Span 80 content (Figure 6D-F). Thus, from the study findings, it was inferred that the vesicle was capable of enhancing permeation across the skin at the explored range of PC (70-95 mg) and Span 80 (5-30 mg). EL3-S80 was finally optimized based on maximum desirability $(0.99)$ and increased permeation flux $\left(187.86 \pm 14.1 \mu \mathrm{g} / \mathrm{cm}^{2} / \mathrm{h}\right)$. The ELs gel that had a 3\% Azone content showed the highest permeation flux $\left(187.86 \pm 14.1 \mu \mathrm{g} / \mathrm{cm}^{2} / \mathrm{h}\right)$ as compared to a $3 \%$ lauric acid-containing gel $\left(117.7 \pm 13.4 \mu \mathrm{g} / \mathrm{cm}^{2} / \mathrm{h}\right)$ and $3 \%$ propylene glycol (PG; $106.7 \pm 7.3 \mu \mathrm{g} / \mathrm{cm}^{2} / \mathrm{h}$ ). In contrast, this parameter was found to be lowest in the plain DS $\left(8.8 \pm 0.76 \mu \mathrm{g} / \mathrm{cm}^{2} / \mathrm{h}\right)$. Additionally, a considerable reduction in activation energy was found (2.63-fold lower than the DS after topical application to the skin). ${ }^{36}$

Utreja et al investigated ELs for the TD of paclitaxel and characterized them with in vitro, ex vivo, and in vivo parameters, with comparisons against a marketed product. The paclitaxel-loaded ELs $(6 \mathrm{mg} / \mathrm{mL})$ showed a 10.8 - and 15.8-fold higher in vitro skin permeation and deposition rate, respectively, as compared to DS. Moreover, a hemolysis study showed $11.2 \% \pm 0.2 \%$ hemolysis as compared to the marketed formulation $(38.0 \% \pm 3 \%)$ without significant irritation as suggested by the Draize test. ${ }^{27} \mathrm{~A}$ further developmental report was published using the same carrier for paclitaxel to investigate its biosafety and cellular uptake (A459 cell lines). ${ }^{37}$ Maximum tolerated doses of paclitaxel ELs and commercial formulations were reported as 160 and $40 \mathrm{mg} / \mathrm{kg}$, respectively. Intracellular uptake was evaluated using a fluorescence activating cell sorting assay (FACS) and fluorescence microscopy techniques. FACS results revealed $94.6 \% \pm 2.5 \%$ fluorescence of the dye acridine orange (AO) loaded in ELs, as compared to the AO solution $(19.8 \% \pm 1.1 \%)$, suggesting there was increased intracellular uptake of ELs. Thus, commercial formulations showed toxicity at doses of $40 \mathrm{mg} / \mathrm{kg}$, suggesting ELs were suitable carriers for the TD of paclitaxel. ${ }^{37}$ Very recently, improved sun-protection effects could be achieved when UV-absorbing compounds were loaded into ELs as compared to conventional sunscreen formulations (consisting of titanium dioxide, which commonly causes irritation) in addition to other benefits. ${ }^{38}$ Thus, it can reduce the risk of skin cancer. ${ }^{39}$

\section{Anti-dermatitis}

Atopic dermatitis (AD) is the dysfunctioning of the SC resulting from excessive TEWL and allergen infiltration into the skin, characterized by allergic symptoms such as redness, itching, and flaking. This chronic disease relapses with characteristic pathological consequences without an established etiology. ${ }^{40,41}$ However, immunological dysfunction and environment-related allergic susceptibilities are prime factors underlying the etiology (interleukin [IL]-4 and -5) by the upregulation of immunoglobulin (Ig)E production. ${ }^{11}$ Recently, cyclosporine and thymopentin (nonsteroidal immunosuppressants) have been identified as first-line drugs used in the treatment of $\mathrm{AD}$, with several side effects from prolonged therapy. ${ }^{42}$ Therefore, such treatments require an alternative medicine for the therapeutic management of AD. Currently, few natural drugs (eg, taxifolin glycoside and dipotassium glycyrrhizate $[\mathrm{KG}]$ ) have been identified to deliver ELs as in AD treatment. ${ }^{11,43}$

Kang et al developed topical ELs for the delivery of taxifolin glycoside using Pep-1 peptide-conjugated ELs (Pep1-EL) for improved skin permeation (in vitro) and therapeutic efficacy (in vivo). The in vitro skin permeation profile was Pep1-EL $>$ Pep1 + EL $>$ EL $>$ solution after $24 \mathrm{~h}$ of study. Pep-1-conjugated ELs markedly increased the permeation flux across the skin and was $\sim 9.4$-fold higher than the DS alone. Thus, Pep-1 conjugation and ELs both demonstrated superior and augmented permeation into the skin after topical application. In vivo therapeutic efficacy of the ELs was evaluated in AD-induced mice by measuring the TEWL. The improvement of TEWL in the EL-treated group was achieved within a week as compared to the gel-treated group ( $>3$ weeks). Moreover, skin hydration was equivalent to controls after treatment with the Pep1EL formulation after 3 weeks suggesting an effective recovery of the skin barrier. ${ }^{11} \mathrm{KG}$ is a water-soluble extract obtained from liquorice root and is reported to be effective 

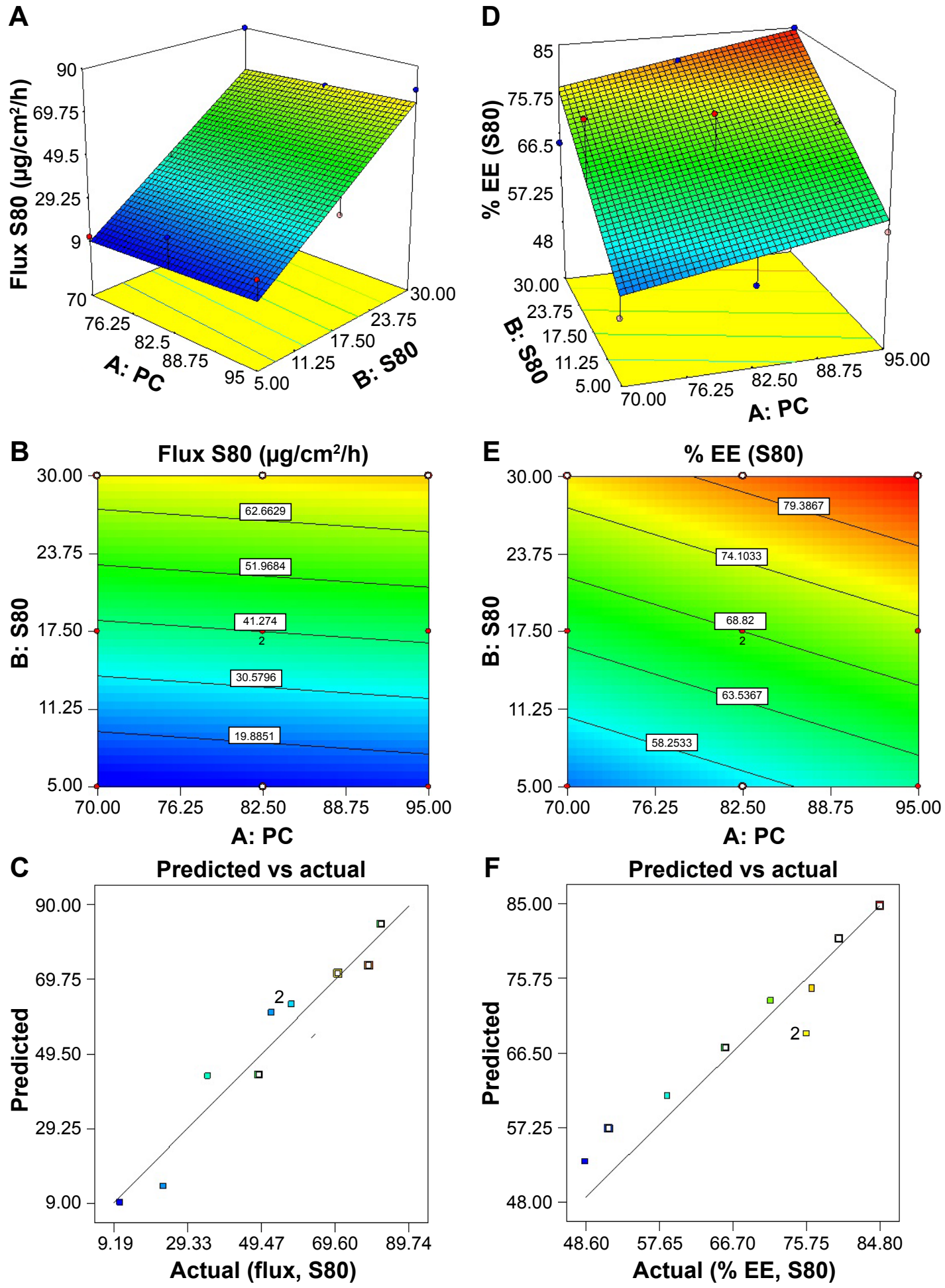

Figure 6 Effect of variable factors (PC and Span 80 [S80]) on permeation flux rate $\left(\mu \mathrm{g} / \mathrm{cm}^{2} / \mathrm{h}\right)$ and \% EE responses of 5-fluorouracil-loaded elastic liposomes assessed by the experimental technique (Design Expert software).

Notes: (A-C) Permeation flux increases with an increase in PC and S80 content, as shown in 3D and contour plots along with actual and predicted graphs; (D-F) \% EE increases linearly with increases in concentrations of PC and S80, as elucidated in the 3D and contour plots. A and B indicate the first independent variable for PC and second independent variable for $\mathrm{S} 80$, respectively.

Abbreviations: PC, phosphatidylcholine; EE, entrapment efficiency.

in acute and chronic dermatitis skin-related consequences, despite sweetening and good emulsifying properties. The authors prepared ELs using soya lecithin mixed with KG $(2: 1,4: 1$, and $8: 1$ ratios) by a solvent evaporation method followed by high-pressure homogenization. Transepidermal permeation and deposition of KG-loaded ELs into the pig skin was evaluated and compared with aqueous DS. KG interacted as well with liposomes, leading to disruption 
and fluidization of the lipid bilayer, and, thus, forming ELs capable of penetrating through membrane pores with a diameter much smaller than their own. Drug deposition into the pig skin was $\sim 5.0$ - and 4.0-fold higher than the DS (0.25\% KG solution) and emulsion $(\mathrm{o} / \mathrm{w})$, respectively. Thus, the relative amount of $\mathrm{KG}$ transported into the skin using ELs was $\sim 40 \%-50 \%$ of the total drug after $12 \mathrm{~h}$ of application. $^{43}$

The application of antisense oligodeoxynucleotide (ASO) in human AD has been exploited due to selective inhibition of translational proteins (mRNA) responsible for the pathogenesis of AD disorders. The hydrophilic and high-molecular-weight $(>350 \mathrm{Da}$ ) nature of ASO has limited its localized delivery to the affected skin. Therefore, the IL-13 ASO with the cationic EL complex was sufficient to pass across the skin barrier by self-deformation, which made it possible for delivery into the atopic region to alleviate and suppress AD conditions. ${ }^{44}$ Topically administered IL-13 ASO/cEL complexes markedly inhibited IL-13 production $(\sim 70 \%$ of the control) in the affected skin portion of the ovalbumin-sensitized murine model of AD with concomitant reduction in IL-4 and IL-5 levels. ${ }^{44}$ Currently, targeted delivery of cetirizine dihydrochloride using ELs has been reported with a twofold increase in permeation $(60.001 \% \pm 0.332 \%)$ as compared to the cream $(33.268 \% \pm 0.795 \%)$ and DS $(32.616 \% \pm 0.969 \%)$. Furthermore, the in vivo therapeutic potential of the optimized formulations against oxazoloneinduced $\mathrm{AD}$ of mice showed a significant reduction in itching score (4.75 itches per $20 \mathrm{~min}$ ) as compared to the cream ( 9.75 itches per $20 \mathrm{~min}$ ) with a considerable reduction in eosinophil count and erythema score of the dermal region. ${ }^{45}$

\section{Antimicrobial: antibacterial, antifungal, and anti-leishmaniasis}

Literature suggests that microorganisms (eg, bacterial and fungal species) present a serious global public health threat. Superficial skin lesions frequently occur leading to vaginitis, mycosis, and cutaneous leishmaniasis of tropical dermatosis. The vaginal route is the most preferred route of drug administration to treat gynecological diseases with high patient compliance. ${ }^{46}$ Conventional formulations with certain limitations, such as short residence time, high drug leakage and instability demand an alternative approach to overcome these limitations. ${ }^{46}$ Candida spp.-mediated infections caused in immunocompromised patients and those with burn wounds have increased to cause a $14 \%-70 \%$ rise in mortality. ${ }^{32,47,48}$ Metronidazole, miconazole, itraconazole, and amphotericin $\mathrm{B}(\mathrm{AmB})$ are commonly used broad-spectrum drugs in local and systemic infections. ${ }^{46}$ Poor water solubility and limited permeation across biological membranes have limited its clinical efficacy. Thus, these potent drugs have been investigated by researchers as suitable candidates for TD using ELs. Researchers have reported that metronidazole loaded in ELs provides intimate adhesion between the mucoadhesive ELs and vaginal mucosa for slow and sustained delivery into the vicinity of bacterial infections. ${ }^{46,49}$

Pandit et al showed enhanced skin (rat) permeation of miconazole nitrate in the treatment of superficial fungal infections confined to the SC, squamous mucosa, and corneal region. ${ }^{50}$ Therapeutic effectiveness was dependent on the drug content transported to the target tissue, type of EA, lipophilicity $(\log P)$, and HLB value..$^{50}$ Permeation parameters increased and followed this order: Span 80> Span 60> sodium deoxycholate $>$ Tween $80 .{ }^{50}$ They envisaged that lipophilic Span 80 (low HLB) had greater affinity to the skin lipids for extraction, leading to enhanced in vitro permeation. Moreover, Span 80 caused a higher degree of vesicle flexibility and deformability.$^{50}$ However, this finding was contradictory to recently published investigations, where Tween 80 (high HLB) was claimed to cause greater deformability and permeation $(72.41 \% \pm 3.2 \%)$ of the ELs loaded with AmB. ${ }^{32}$ Similarly, itraconazole (IT) - due to high lipophilicity (log $P>5.5)$, poor aqueous solubility $(1 \mu \mathrm{g} / \mathrm{mL})$, and relatively high molecular weight $(\sim 705 \mathrm{Da})$ - received attention from researchers for TD using ELs in the treatment of superficial or cutaneous fungal infections. ${ }^{4,36}$ An IT-hydroxylpropyl$\beta$-cyclodextrin complex loaded EL enhanced permeation across the skin and retained antifungal activity as compared to the plain DS. ${ }^{51}$

Recently, poorly soluble and low-permeable AmB was investigated to treat cutaneous fungal infections and leishmaniasis. ${ }^{32}$ Commercially available salt (parenteral) is responsible for serious nephrotoxicity and several side effects. ${ }^{52}$ Moreover, the effect of EL components on several parameters was studied (eg, deformability, vesicle size, \% EE, in vitro drug release, and ex vivo and in vivo performance). Tween 80-based ELs showed maximum deformability, high $\% \mathrm{EE}(75 \%)$, smaller vesicle size $(107 \pm 8.0 \mathrm{~nm})$, low polydispersity index (0.078), and zeta potential $(-3.0 \pm 0.2 \mathrm{mV})$ in monomeric form. AmB-loaded ultradeformable liposomes (AmB-UDL) exhibited a 40-fold higher AmB accumulation into the human skin than Fungisome ${ }^{\circledR}$ after $1 \mathrm{~h}$ of non-occlusive application. It was observed that Candida albicans, Aspergillus spp., and clinical isolates of some other fungal strains were more susceptible to AmBUDL than normal mammalian cells. Furthermore, AmBUDL displayed $100 \%$ and $75 \%$ anti-leishmanial activity 
against promastigote and amastigote at a $1.25 \mu \mathrm{g} / \mathrm{mL}$ dose, respectively. ${ }^{32}$

Our research laboratory explored stable nanoemulsions for the TD of AmB in the treatment of superficial cutaneous infections in order to attain enhanced skin permeation using excipients holding innate antifungal activities against Candida spp. and Aspergillus spp. that resulted in effective and efficient AmB delivery. ${ }^{52,53}$

\section{Antioxidants}

Chemically, antioxidants are reducing agents of prime importance for therapeutic applications obtained from plants (citrus fruits). Excessively generated free radicals (which are aggressive factors) such as hydrogen peroxide, superoxide anions, and singlet species, as by-products of physiological metabolic processes, play a major role in many abnormal pathological reactions (eg, immune suppression, photo-carcinogenesis, and photo-aging) of skin damage (or cutaneous damage) ${ }^{54,55}$ Recently, Nava has made an attempt to use natural flavonoids such as catechin (polyphenolic compound) and naringenin (a flavanone from citrus fruit) as an antioxidant (free radical scavenger) to prevent the oxidation of cutaneous disorders. ${ }^{54}$ However, physicochemical profiles of these promising compounds need to be addressed for the successful transport of the drugs to the desired site of action across the SC barrier. The hydrophilic nature of catechin and the poor oral bioavailability (BA) of naringenin ( $-5.8 \%)$ are envisaged for TD. ${ }^{55,56}$ Despite the diverse applications of D-catechin (due to its anticarcinogenic and antibacterial activities, and its antiobesity effects) and naringenin, these have been explored for potential antioxidant properties and formulated in ultradeformable ELs as TD vehicles for skin damage. de Gruijl developed conventional and deformable ELs loaded with catechin and subsequently characterized them for particle size, zeta potential, \% EE, and in vitro drug-release behavior. They evaluated their permeation and deposition using porcine skin. ${ }^{56}$ Results revealed that both formulations had particle sizes in the range suitable for TD, as determined before and after the freeze-drying process. Moreover, deformable ELs had higher \% EE ( $50 \%)$ due to their hydrophilic nature and more aqueous volume in deformable ELs than conventional liposomes ( 36\%). Similarly, the permeation flux was enhanced once ELs were deformable, as compared to conventional liposomes, with more drug deposition into the porcine skin. However, no catechin passed across the skin from the applied DS. ${ }^{56}$

Naringenin-loaded ELs were also characterized for particle size and \% EE. Further evaluation of drug deposition into the rat skin showed significantly increased drug deposition $\sim 7.3$ - to 11.8 - and 1.2- to 1.9-fold higher than the saturated aqueous solution of naringenin and Tween 80 -assisted solubilized naringenin, respectively. In addition, storage stability studies (at $4^{\circ} \mathrm{C}$ ) revealed a $98.89 \% \pm 3.9 \%$ drug content level after 3 months. Furthermore, studies demonstrated no potential irritation after topical application. ${ }^{56}$ It can be concluded that deformable ELs for both antioxidants are suitable for safe and effective TD.

\section{Photo-protective agents}

Presently, public awareness regarding the harmful effects of UV radiation (from sunlight) is constantly increasing due to depletion of the ozone layer. Regular and chronic exposure to intense UV radiation is deleterious to human health, resulting in sunburns, DNA damage, photoaging, hyperpigmentation, and cutaneous cancer. ${ }^{57,58}$ The most known aggressive factors such as reactive oxygens (via hydrogen peroxide and superoxide anion free radicals) play a major role in carcinogenesis, aging, and skin damage, resulting in the loss of structural integrity of the skin. ${ }^{59}$ Therefore, natural and synthetic compounds have been reported for several sunprotective effects. Quercetin (a flavonol) and benzophenone-3 (organic compounds approved by the US Food and Drug Administration) compounds have been delivered topically using ELs and conventional liposomes. ${ }^{13,59}$ Initially, inorganic compounds were frequently used in children due to occlusive and opacity whereas, nowadays, organic compounds are more effective owing to their significant UV-absorbing nature by converting to lower energy that is harmless to the human body. Conventional formulations (eg, sunscreen creams and lotions) are unable to deliver agents to the deeper portion of the skin and remain for a very short period of time after topical administration. Conclusively, benzophenone-3 and quercetin have been investigated for effective and efficient delivery into the deeper portion of skin by employing mucoadhesive deformable ELs against UV-B radiation. ${ }^{13,59}$

\section{Anti-psoriatic, anti-inflammatory, and anti-acne drugs}

Currently, researchers have reported the management of acne, psoriasis, inflammation, and other cutaneous keratoses using colchicine, methotrexate, and tretinoin for topical delivery (Table 3). ${ }^{59-64}$ These drugs have certain clinical and pharmaceutical limitations when delivered in conventional dosage form or using conventional liposomes. Several attempts have been made to resolve their shortfalls 
Table 3 Drugs associated with physicochemical and clinical problems

\begin{tabular}{|c|c|}
\hline Drugs & Limitations/problems \\
\hline Methotrexate & $\begin{array}{l}\text { I. Mucosal ulcer, bone marrow depression, stomach } \\
\text { inflammation } \\
\text { 2. Loss of appetite, induced hepatic fibrosis, liver } \\
\text { cirrhosis }^{60} \\
\text { 3. In dissociated form at } \mathrm{pH} 7.4\end{array}$ \\
\hline Tretinoin & $\begin{array}{l}\text { I. Least aqueous solubility, skin irritation } \\
\text { 2. Instability in light, air, and heat } \\
\text { 3. Erythema, peeling, and burning effects }{ }^{61} \\
\text { 4. Susceptible to sunlight }\end{array}$ \\
\hline Colchicine & $\begin{array}{l}\text { I. Risk/benefit ratio is high } \\
\text { 2. Gastrointestinal side effects such as nausea, } \\
\text { vomiting, and diarrhoea }{ }^{62} \\
\text { 3. Unsuitable for oral administration when given for } \\
>\text { I week due to accumulation in bone marrow, } \\
\text { leading to bone marrow depression }{ }^{63} \\
\text { 4. Not suitable for renal dysfunction and } \\
\text { neuromyopathy } \\
\text { 5. Intravenous administration associated with potential } \\
\text { side effects such as necrosis, cytopenias, and } \\
\text { disseminated intravascular coagulation and death }{ }^{64} \\
\text { 6. Narrow therapeutic index } \\
\text { 7. Lethal at doses }>0.8 \mathrm{mg} / \mathrm{kg} \\
\text { 8. Dose-dependent side effects }\end{array}$ \\
\hline
\end{tabular}

with a desired set of goals. In brief, we have compiled limitations of these potent drugs in Table 3 that could be helpful for pharmaceutical scientists engaged in formulation design.

Colchicines, methotrexate (MTX), and tretinoin were fabricated into ELs for effective and safe delivery in the treatment of cutaneous disorders. Researchers have investigated a complex mixtures of colchicines with $\beta$-cyclodextrine for improved permeation rates and sustained delivery. This complexation technique enhanced permeation fluxes and drug deposition by 6- and 12.4-fold for the sustained delivery of the colchicines ${ }^{64}$ Singh et al suggested the sustained delivery of colchicines using EL for the treatment of gout and other related diseases (eg, psoriasis and dermatological disorders). Their study reported $7-11$ and 12.5 -folds for higher permeation fluxes and drug deposition in rat skin as compared to DS, respectively, indicating enhanced colchicine permeation for better therapeutic efficacy. Moreover, their findings were corroborated with CLSM for augmented skin penetration $\left(\sim 12.0 \mu\right.$ m-deep skin penetration). ${ }^{65}$

Similarly, MTX encapsulated in ELs for controlling calcitrant psoriasis was reported with PC and hydrogenated Phosphatidylcholine (HPC) at different ratios of lipid-surfactants (2:1 and 4:1). KG was used as the surfactant due to its emulsifying properties. Permeation fluxes across the pig skin were 3-4 times higher than for DS as well as conventional liposomes, with $50 \%$ drug deposition at the end of the study. It is interesting to note that there was no difference in permeation parameters between the two types of lipids (PC and HPC) based on ELs (PC-KG-EL and HPCKG-EL). ${ }^{60}$ Thus, MTX-loaded ELs showed improved in vitro evaluation (size and drug release) and increased drug deposition into the epidermis and dermis layers of porcine skin..$^{59}$ Table 3 summarizes some of the problems identified with MTX, tretinoin, and colchicines. ${ }^{59-66}$

Topically delivered tretinoin was investigated for enhancing skin permeation in dermal delivery using different hydrophilic penetration enhancers such as labrasol, transcutol P, PG, and commercially available Oramix ${ }^{\circledR}$ NS 10 (OrNS10). All of these surfactants showed increased cutaneous accumulation and transdermal delivery of the tretinoin except PG ${ }^{67}$ Recently, an experimental design technique was employed as an optimizing tool for the preparation of ELs loaded with tretinoin in topical delivery. PC and the transcutol $P$ ratio was used as an independent variable (levels), and $\% \mathrm{EE}$ and drug release as the response parameters in the statistical optimization. Bavarsad et al reported that $79 \%-93 \%$ EE was observed with $\mathrm{F} 7$ formulations responsible for maximal drug release. Enhanced skin permeation flux was achieved owing to transcutol P-mediated solubilization. The optimized formulation (24:7) demonstrated an $~ 3.73$-fold higher permeation flux $\left(3.29 \pm 0.08 \mu \mathrm{g} / \mathrm{cm}^{2} / \mathrm{h}\right)$ across the rat skin as compared to the commercial cream $\left(0.88 \pm 0.04 \mu \mathrm{g} / \mathrm{cm}^{2} / \mathrm{h}\right){ }^{6}$ Several other miscellaneous drugs were reported to be delivered using EL, as summarized in Table 4.9,67-76

\section{Transdermal delivery Transdermal ELs: promising advantages and challenges}

The transdermal delivery system is intended for systemic delivery, offering numerous advantages such as noninvasiveness, hepatic first-pass avoidance, suitability for unconscious patients, patient friendliness, and modified drug release. In general, transdermal delivery is restricted to low-molecular-weight hydrophobic drugs $(<500 \mathrm{Da}){ }^{77}$ In transdermal delivery, significant percutaneous systemic absorption with considerable drug accumulation is a prerequisite. Moreover, drugs are forced to pass through the relatively narrow diffusional window defined by the contact area of the applied formulation. The challenge is to find a new nanotechnological means of transdermal delivery system to enhance systemic absorption of promising molecules, such as drugs with a hydrophilic nature (low $\log P$-value), lack of stability at gastric $\mathrm{pH}$, prone to first-pass hepatic 


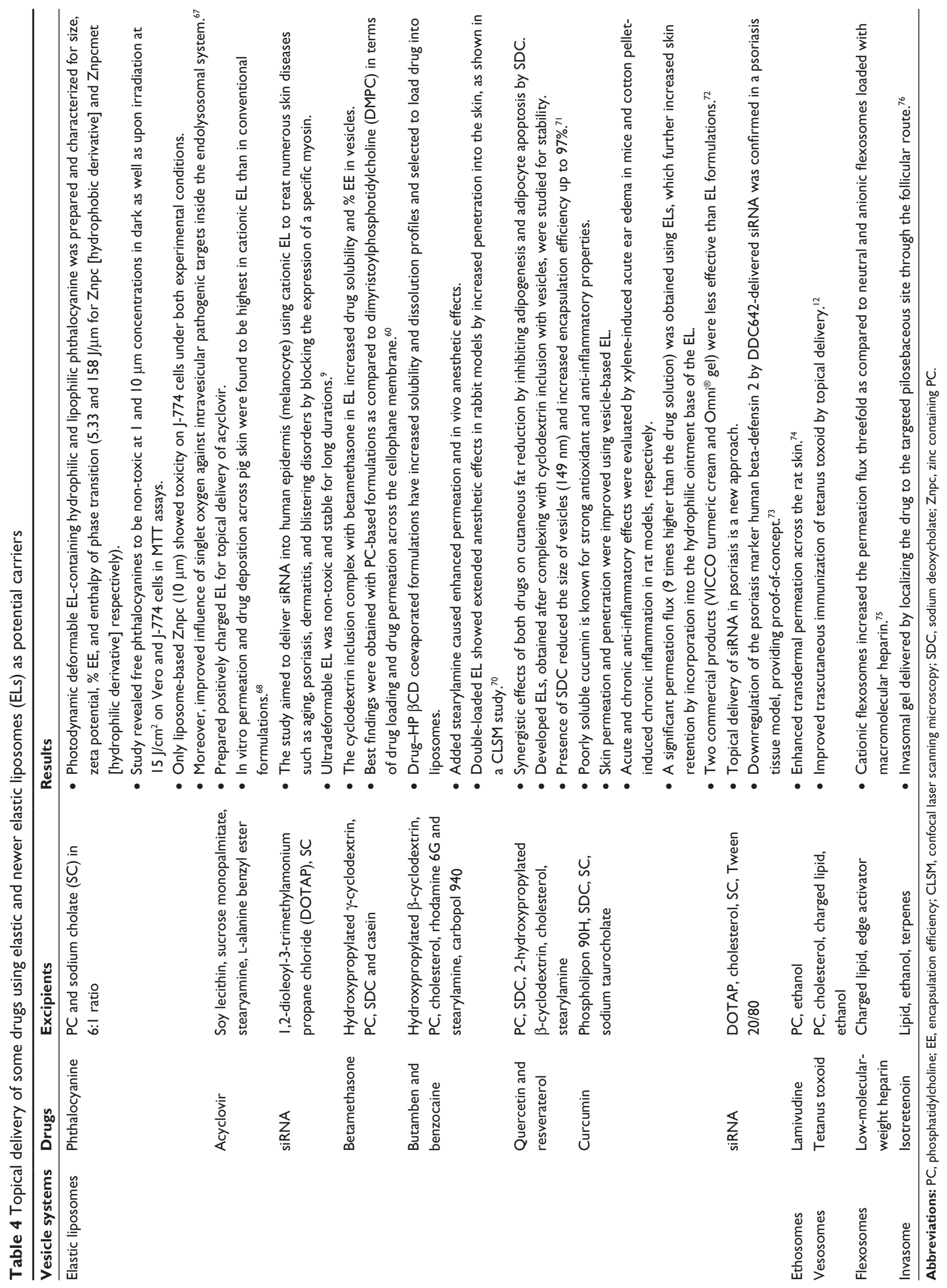


metabolism (enzymatic degradation), irritating the gastric lumen, prime substrate of intestinal P-gp efflux system, narrow absorption windows, and poor oral BA. Thus, a series of hydrophilic molecules have been investigated to be delivered transdermally, employing ELs for local and systemic effects.

The SC layer restricts sufficient drug delivery to the systemic site of action and could be achieved by modifying certain physical, chemical, and formulation properties. Physical (microneedle, electroporation, and ultrasound), chemical (chemical permeation enhancers), and formulation design-based approaches (vesicular carriers like liposomes, ELs, transferosomes, lipid nanoparticles, and polymeric nanoparticles) have recently been investigated by several authors. A combination of methods (physical and formulation based) has also been studied, with more beneficial outcomes. Several drugs are summarized for TD, with enhanced permeation using ELs alone or in combination with physical methods.

\section{Anticancer drugs}

A combined approach using microneedle-pretreated ELs of poorly water-soluble and high-molecular-weight (807.9 Da) docetaxel is an interesting technique. Transdermal fluxes achieved were in the range $1.3-1.4 \mu \mathrm{g} / \mathrm{cm}^{2} / \mathrm{h}$, where the skin was pretreated with microneedles before EL application. It is noteworthy that the obtained lag time was significantly decreased $(\sim 70 \%)$ as compared to conventional liposomes using microneedles. These findings suggested that the combined effect of improved skin permeation was the reason for the success of such molecules. ${ }^{78}$ Recently, 5-FU was formulated in thermosensitive stealth liposomes (TSLs) and the pharmacokinetic profile was determined by triggering drug release upon hyperthermia by using ultrasound as a physical method. Complexing 5-FU with copper polyethylenimine appeared to be an attractive strategy to improve 5-FU retention in TSLs in vitro and in vivo. TSLs allowed heat-triggered drug release within $10 \mathrm{~min}$ at $42^{\circ} \mathrm{C} .{ }^{79}$ Thus, physical pretreatment followed with a new formulation is a new therapeutic approach for augmented drug permeation across the skin for systemic drug delivery.

\section{Antihypertensive drugs}

Several antihypertensive drugs have been used for the management of cardiovascular disorders (eg, hypertension, angina pectoris, and myocardial infarction) using transdermal ELs. Propranolol hydrochloride, valsartan, and nifedipine are a non-selective $\beta$-adrenoreceptor blocker, angiotensin II receptor antagonist (selective AT-I antagonist), and calcium channel blocker, respectively. ${ }^{13,80,81}$ The physicochemical (low solubility, high molecular weight, and short half-life) and physiological (gastric disturbances and first-pass hepatic metabolism) limitations of these drugs led to the selection of suitable alternative routes of delivery to overcome their inherent problems. ${ }^{13,80,81}$ Propranolol hydrochloride shows low oral BA $(15 \%-23 \%)$ and highly variable hepatic firstpass metabolism, which are potential rationales to fabricate them into EL for TD and eventual formulations exhibiting better skin penetration across the rat skin as visualized on CLSM assessment. ${ }^{13}$ Valsartan, with almost similar oral BA $(\sim 25 \%)$ and high molecular weight (435.5 Da), was developed into ELs for systemic delivery using an experimental design technique. ${ }^{80}$ Statistically, optimized valsartan-loaded ELs showed a superior enhancement ratio (33.97 \pm 1.25$)$ across the rat skin than rigid conventional liposomes. This finding was further corroborated using a CLSM study for better penetration of the carrier into the different strata of the skin as a tracking tool for the drug. They suggested that ELs accentuated transdermal flux and could be used as an effective carrier for transdermal delivery in the treatment of hypertensive disease. ${ }^{80}$

\section{Steroidal and non-steroidal analgesic drugs}

Some steroidal (dexamethasone) and non-steroidal analgesic and anti-inflammatory drugs (NSAIDS) can be delivered transdermally. ${ }^{22,82,83}$ These drugs are used in the treatment of moderate to severe pain, severe fever, postoperative pain, visceral pain of cancer, edema of traumatic condition, inflammation, and related consequences. However, many side effects have been associated with their use in conventional oral dosage, which limits their clinical efficacy. These drugs are associated with gastric disturbances, need frequent administration due to their short biological halflife (4-6 h of ketorolac) leading to several side effects, and there is significant patient noncompliance. ${ }^{22,83}$ A report has been published on the delivery of dexamethasone loaded in an EL carrier transdermally, followed by an in vivo study performed in a carrageenan-induced paw edema rat model to show antiedema activity that was better than in conventional liposomes and ointments. Moreover, the study further corroborated the permeation flux and penetration into the rat skin using fluorescence probes (rhodamine 123 and 6-carboxy fluorescein dye). ${ }^{22}$ Similarly, meloxicam and ketorolac trimethamine showed enhanced permeation 
across shed snake skin and human skin, respectively. ${ }^{82,83}$ A good correlation between the permeation flux (permeation flux of $0.278 \mu \mathrm{g} / \mathrm{cm}^{2} / \mathrm{h}$ ) and TEWL was found.$^{83}$ Another report studied ketorolac interactions (chemical stability) with the lipid bilayer of ELs using double-chain (sucrose laurate ester) and single-chain surfactants (octaoxyethylenelaurate ester). ${ }^{84}$

Hydrophilic diclofenac sodium has been delivered in ELs and conventional liposomes to observe the effect of vehicles on in vitro drug-release patterns. Studies have shown that propylene-containing ELs were optimal for drug release as compared to conventional liposomes. ${ }^{85}$ Recently, tramadol HCl-loaded ELs prepared by solvent evaporation method were characterized for morphological assessment, particle size, zeta potential, drug concentration, and ex vivo drug permeation. The vesicle size and zetapotential values obtained were $152.4 \mathrm{~nm}$ and $-22.4 \mathrm{mV}$, respectively, whereas the $\% \mathrm{EE}$ of the optimized formulation was $79.71 \% \pm 0.27 \% .{ }^{1}$ Thus, ELs hold promise as a carrier suitable for the effective delivery of cardiovascular and analgesic drugs.

\section{Local anesthetic drugs}

The controlled and sustained release of local anesthetic drugs using nanocarriers can improve drug action, with reduced systemic toxicity. Butamben (BTB) is highly lipophilic and a congener of benzocaine studied for topical and dermal delivery. ${ }^{85}$ The drug is characterized with a toxic effect on systemic absorption in the short term. ${ }^{86}$ Permeation fluxes were $6.95 \pm 1.60$ (10\% BTB), $23.17 \pm 6.09(10 \%$ BTBLUV), and $29.93 \pm 6.54 \mu \mathrm{g} / \mathrm{cm}^{2} / \mathrm{h}(10 \%$ BTBLUV-EL $)$ for $10 \%$ BTB, $10 \%$ BTBLUV, and 10\% BTBLUV-EL, respectively, with corresponding time lags of $1.90 \pm 0.48$, $1.23 \pm 0.28$, and $1.57 \pm 0.38 \mathrm{~h}$, respectively. Furthermore, the permeability coefficients $\left(10^{-3} \mathrm{~cm} / \mathrm{h}\right)$ were $1.02 \pm 0.23$ (10\% BTB), $2.96 \pm 0.77$ (10\% BTBLUV), and 4.14 \pm 0.9 (10\% BTBLUV-EL), suggesting improved permeation flux. Thus, results demonstrated enhanced permeation using vesicular gel formulations as compared to plain gels. ${ }^{86}$ Likewise, lidocaine encapsulated in ELs was coated with the cationic polymer chitosan for improved stability (at $4^{\circ} \mathrm{C}$ for 3 months of storage conditions) and skin permeation. ${ }^{70,87}$

Table 5 summarizes a review of several drugs reported for transdermal delivery using ELs and recently reported new ELs. ${ }^{88-98}$ Furthermore, these latest ELs were tabulated (Table 6) with valuable information, such as definition, composition, classification, advantages, and inherent limitations. ${ }^{14}$

\section{Drug delivery to the brain: antimigraine and antiparkinson drugs}

Drug delivery to the central nervous system (CNS) through nasal administration has been achieved by involving paracellular (intercellular spaces and tight junction), transcellular (passive and active diffusion including transcytosis), neuronal transport, and trigeminal nerve systems. ${ }^{99,100}$ Thus, this route may avoid hepatic first-pass metabolism and circumvents the blood-brain barrier (BBB) in the treatment of brain disorders.

Drugs acting on the CNS need to pass across the BBB after oral administration. A migraine is a neurological disease characterized with recurrent headache (typically existing for 4-72 h), accompanied with frequent nausea, headache, vomiting, photophobia, phonophobia, and gastric disturbances. ${ }^{101,102}$ Triggering neuropeptides is responsible to produce painful inflammation in cranial vessels and the dura mater. ${ }^{101}$ An episodic migraine is considered a precursor of chronic migraines. ${ }^{102}$ Thus, migraines could be progressive and necessitate sustained-release formulations for treatment of the disorder. Garg et al developed ELs to deliver the 5-HT1B agonist rizatriptan for transdermal sustained release, followed by in vivo activity in a mouse model using morphine (withdrawal-induced hyperalgesia model). The optimized formulation loaded with rizatriptan showed threefold higher activity than the DS. Moreover, an in vitro skin permeation study revealed that all ELs exhibited 8- to 19-fold enhanced permeation flux, as compared to DS, across the rat skin. Drug deposition into the skin was found to be 10-fold higher than that with the DS. ${ }^{101}$ Likewise, sumatriptan succicinate was delivered transdermally employing lipid vesicles comprising 1,2-dioleoyl-sn-glycero-3-phosphocholine (DOPC) or $1-\alpha$-phosphatidylcholine dilauroyl (DLPC) phospholipids. The permeation flux was $\sim 4$-fold higher than with the DS. ${ }^{16}$ DLPC vesicles showed increased elasticity and permeation flux of sumatriptan than the DOPC-based vesicle. This difference may be due to the varied bilayer thickness of DLPC and DOPC that leads to DLPC bilayers with more elasticity as compared to DOPC. The length of the acyl chain of PC (DLPC: C12; DOPC: C18) seems to have a considerable effect on the elasticity and permeation across the skin behavior of the fluid-state ELs. ${ }^{7}, 16$

Lipophilic pergolide ( $\log P=2.3$ and molecular weight of $314.5 \mathrm{Da}$ ) has been used in the treatment of Parkinson's disease. ${ }^{103}$ This is a suitable candidate owing to its potency and the low therapeutic level required. The drug undergoes first-pass metabolism and intersubject variation of plasma level after oral administration, leading to poor oral BA. 


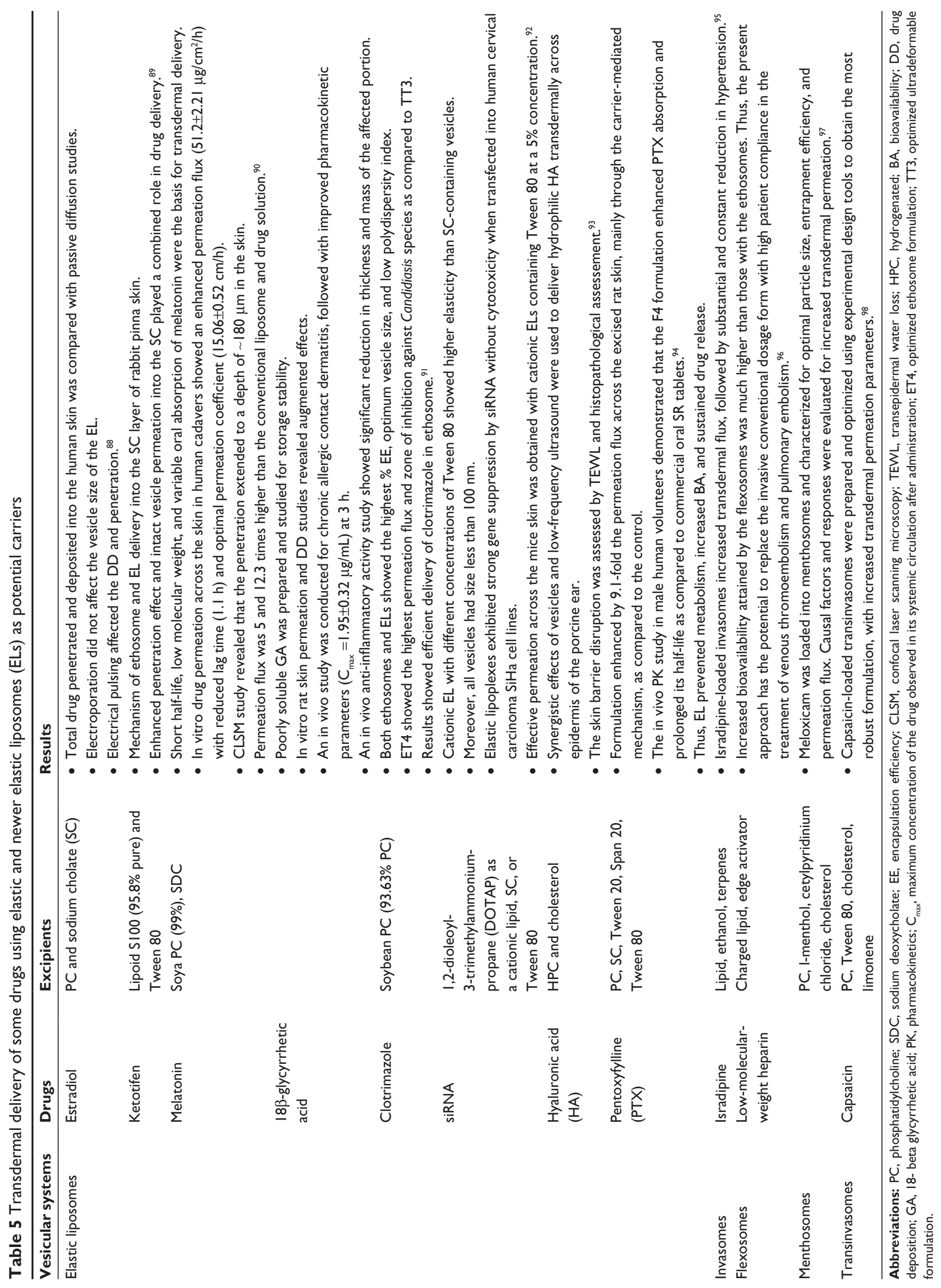


Table 6 A summary of conventional and newer vesicular systems

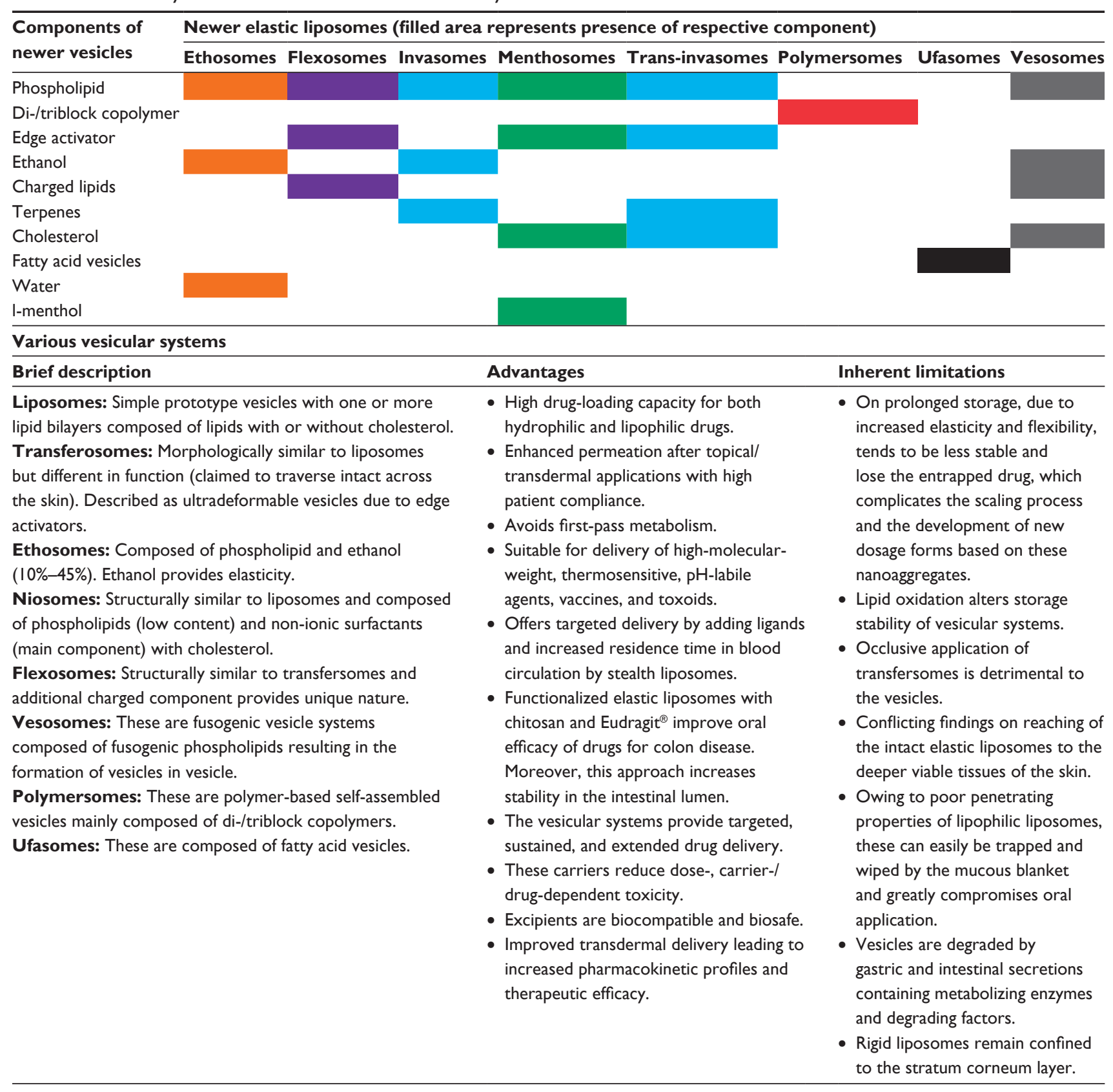

Both issues were overcome by developing a TD system using ELs. The study showed that elastic vesicles (L-595/PEG-8-L/ sulfosuccinate [70/30/5]) improved transport steady-state flux (6.2 times) rates as compared to rigid liposomes. ${ }^{104}$ Today, there still exists scarcity of in vivo data studied in animal and human models for the transport of pergolide across the skin. Thus, TD of pergolide would be a great alternative to treat Parkinson's disease by providing constant and controlled input of the drug. This may significantly reduce the side effects of anti-Parkinson's treatment arising due to fluctuating drug plasma levels.

\section{Vaccines and toxoids}

One of the main achievements in modern medicine is effective vaccination in the treatment of several infectious disorders (bacterial and viral diseases). ${ }^{105}$ Vaccination activates particular parts of the immune system to express specific immune responses, followed by induction of long-lasting immunological memories to defend against subsequent infectious attacks. ${ }^{106}$ Most of the available vaccines are for intramuscular delivery, which is painful and requires an aseptic technique as well as skilled and trained personnel for administration. Thus, TD of such biological products (vaccines and toxoids) 
is suitable as a non-invasive approach, compared to conventional methods, with numerous obvious advantages such as increased patient compliance, reduced systemic side effects, and constant plasma concentration. Moreover, this approach is free from the need for any trained and skilled personnel, cost-effective products, and feasibility, even for children and unconscious patients for friendly and economical drug delivery. In the last decade, Ding et al reported antigens such as vaccines and toxoids. Depending on the type of the antigen, the dose to be delivered, immunization schedule, presence of costimulatory factors, and EL composition, the immunization of antigens loaded in ELs elicits an effective immune response with serum IgG levels comparable to those obtained after subcutaneous injection. ${ }^{107}$

Transcutaneous immunization (TCI) is a novel technique and requires simple introduction of the antigens to host tissue by topical application to the skin. ${ }^{10}$ This offers ease of administration and the capability to elicit a robust immune responses as compared to conventional painful (needle injections) methods prescribed in equivalent doses. ${ }^{108}$ The densely present epidermal antigen-presenting cells (APC) and migratory $\mathrm{T}$-lymphocytes are collectively termed as skin-associated lymphoid tissue and constitute a cutaneous immune system which is a crucial defense in displaying cell-mediated immune (CMI) response and humoral immune response. ${ }^{109,110}$

In earlier investigations, hepatitis B surface antigens loaded in ELs showed increased efficiency, enhanced permeation, and effective immune-adjuvant properties as compared to conventional liposome formulations. ELs have portrayed improved vaccine delivery. Moreover, researchers have compared the formulations in terms of antigen titer (humoral response) with an intramuscularly administered alum-adsorbed HBsAg solution and observed relative systemic $\operatorname{IgG}$ and secretory IgA responses. ${ }^{12}$ Furthermore, Mishra et al studied the in vitro qualitative and quantitative uptake of HBsAg (drug) by murine dendritic cells (DCs) generated from bone marrow mononuclear cells followed by the visualization of internalization between vesicle and DC cells using fluorescence microscopy. The uptake kinetics of antigen-loaded EL vesicles by DC cells were estimated by flow cytometry and results showed that HBsAg-loaded ELs, as antigen-delivery modules, and DCs as APC, were able to generate a protective immune response. ${ }^{23}$ It is interesting to note that the authors further investigated sequential studies using two different vesicular systems such as ethosomes (or vesicular systems containing a higher content of ethanol) and ELs loaded with HBsAg to estimate the qualitative and quantitative uptake by DC cells. The results showed that ethosomes ( $45 \%$ ethanol) had a higher degree of internalization and immunization as compared to ELs. ${ }^{111}$

Tyagi et al suggested improved immunogenicity of carboxyl-terminal (19 kDa) fragments of merozoite surface protein-1 (PfMSP-119) of Plasmodium falciparum after subcutaneous administration using ELs. ${ }^{12}$ Humoral and CMI responses were exhibited by the topical application of PfMSP-119-loaded EL. An alum-adsorbed PfMSP-119 solution and PfMSP-119-loaded conventional liposomes were administered intramuscularly and via a topical route, respectively, followed with comparisons against the vehicle as a control. The findings suggested greater TCI by ELs by inducing robust and perdurable IgG-specific antibodies and cytophilic isotype responses. Moreover, results showed sizeable CMI-activating factors (eg, IFN- $\gamma$ ) as a crucial player to confer resistance to asexual blood-stage malaria with ELs. Fluorescence microscopy and histopathological assessment suggested major skin permeation and biodistribution to demonstrate efficient delivery of malarial antigen using ELs to immunocompetent Langerhans cells and lymphatics. ${ }^{12}$

Several studies showed the application of antigencontaining occlusive patches to induce strong immune responses in an animal model as well as in human volunteers. ${ }^{13,114}$ Moreover, the success of vaccination mainly depends on the nature (type) of the antigen and high doses used in occlusive patches. Thus, an urgent demand still persists to improve antigen (toxoids) delivery into the skin. However, the main hurdle in TCI for successful vaccination is penetration of the SC layer of the skin. Thorne et al have reported the development of toxoid-loaded ELs for TCI, using diphtheria toxoid (DT) as a model candidate. The reason for using ELs to deliver DT is that it is unable to elicit immunogenic responses in plain solution form, which could be due to inefficient delivery into the skin. DT-loaded ELs showed higher stability at $\mathrm{pH} 5$ and revealed higher association with preserved antigenicity. ${ }^{100}$

\section{Nasal delivery of ELs}

Normal mucociliary clearance rapidly clears nasally applied materials, leading to reduced contact time of drugs in the mucosa. However, several attempts have been made to prolong the retention time by employing mucoadhesive materials, such as positively charged chitosan, which could increase the BA of intranasally administered vesicles. ${ }^{115}$ Chitosan-mediated tight-junction opening (or the disruption of proteins by translocation from the membrane to the cytoskeleton) is considered as the main mechanism for ionic 
charge transfer between the positive charge of the chitosan and negative charge of the glycocalyx. ${ }^{116}$ The absorption process is a combined complex mechanism involving paracellular, intercellular, active, and passive transport (as discussed in the CNS section).

ELs are ultradeformable stress-responsive vesicular delivery systems suitable for pulmonary delivery of hydrophilic salbutamol as a model candidate for nasal delivery. The aerosol was generated by an air-jet ultrasonic method of salbutamol loaded in ELs and studied for stability. In vitro drug-release studies revealed that only $30 \%$ of the total entrapped drug was retained, which was further increased by up to $53 \%$ by liposomes containing cholesterol. In contrast, liposomes entrapped $60 \%-70 \%$ of the total drug even in the absence of ethanol or Tween 80 . Conclusively, it was observed that the materials used in ELs are responsible for vesicle instability at the time of nebulization and cause more drug leakage. ${ }^{117}$

\section{Oral delivery of ELs}

Oral delivery is the most preferred route of administration for numerous drugs with high patient compliance. Despite several advantages, the route is unsuitable for vesicular systems. The poor penetration ability of lipophilic liposomes has greatly limited their oral delivery and, thereby, has been wiped by the thick $(100-800 \mu \mathrm{m})$ intestinal mucous layer (serving as a hydrophilic blanket). ${ }^{118}$ For the purpose of gastrointestinal tract targeting, the liposomal surface was manipulated by the polymer coating (chitosan, pectin, and Eudragit $^{\circledR}$ ), which resisted degradation in hostile gastrointestinal environments and increased stability in the gastric and intestinal fluids. ${ }^{119} \mathrm{Li}$ et al investigated the functionality of mucous-penetrating liposomes and explored their intestinal cellular uptake mechanism. ${ }^{118,120}$

D-catechin is the most potent natural antioxidant belonging to the flavonoid category. The drug was encapsulated in ELs and studied for brain delivery after oral administration. Drug release was studied in simulated gastrointestinal fluids, which demonstrated sustained delivery of D-catechin, as compared to the free drug administered via the same route. A distribution study revealed that there were 2.7 and 2.9 times higher catechin accumulation from ELs in the cerebral cortex and hippocampal regions, respectively, as compared to that with plain DS. Moreover, higher amounts of catechin were detected in the striatum and thalamus. ${ }^{121}$

\section{Future directions}

This article focused to review ELs (a novel nanocarrier) as a promising drug-delivery carrier in the management of various diseases. Numerous researchers have realized the potential applications of ELs as compared to other vesicular systems, wherein enhanced permeation, improved BA, increased solubility, higher encapsulation, reduced side effects, and improved pharmacokinetic profiles have been reported with certain limitations. However, the success of EL-based formulations is only possible if pharmaceutical industries take up the development as well as guarantee widespread use of vesicular EL systems. Furthermore, this current comprehensive review suggests that there is still a scarcity of informative clinical data for the use of such carriers. Convincing preclinical and clinical studies are required to collect the data necessary to establish the safety profile of challenging drugs before industrial scale-up based on low-risk/high-benefit ratios. Moreover, researchers need to explore the synergistic activity of excipients and loaded drug(s), which may be due to the electrostatic charge or innate activity of the excipients. In addition, research needs to be conducted to determine the final localization of ELs with an intact vesicle. Thus, nonionic surfactant and lipid-based drug delivery attract more interest from researchers and scientists working in related domains to improve the pharmacokinetic and pharmacodynamic profile of drugs.

\section{Conclusion}

The present review comprehensively compiled informative data for ELs employed as novel drug-delivery carriers. This carrier is of great interest for formulation scientists working in related domains, wherein in vitro and in vivo findings suggest profound applications to improve physicochemical, pharmacodynamics, and pharmacokinetic profiles of numerous drugs in animal and human studies. Primarily, the composition of the ELs has a significant effect on therapeutic efficacy of the promising drug molecules when administered using transdermal, topical, oral, nasal, CNS, and biological products (vaccines and toxoids). This has extensively been exploited for the delivery of several drugs and vaccines in the treatment of various diseases effectively and efficiently, suggesting the versatile application of the ELs. Significant data have been reviewed to provide valuable information (eg, permeation flux and enhancement ratios) on the permeation behavior of drug-loaded ELs intended for topical and transdermal applications. However, the carrier composition still needs to be explored experimentally for drugs acting on the CNS to attain increased elasticity, stability, and CNS targeting. Moreover, the optional ingredients (eg, ethanol, PEG400, complexing agent [eg, cyclodextrine] and gelling agents) have to be further established as a new trend for improving stability and elasticity for both of the vesicles as 
emphasized in this review. Despite comprehensive research to date, conflicting outcomes continue to be published pertaining to the effectiveness of ELs. Several issues still remain unexplained, such as vesicle stability following topical administration, storage stability and retention of intact vesicle structures in the deeper portion of the skin, and suitable vesicle composition, satisfying both elasticity and stability. Nonetheless, it is clear that ELs have a bright future in improving drug delivery for numerous clinical applications.

\section{Acknowledgment}

The authors thank the Faculty of Pharmacy, Sachchidananda Sinha College, Aurangabad, Bihar, for providing constant support with manuscript writing.

\section{Disclosure}

The authors report no conflicts of interest in this work.

\section{References}

1. Singh S, Vardhan H, Kotla NG, Maddiboyina B, Sharma D, Webster TJ. The role of surfactants in the formulation of elastic liposomal gels containing a synthetic opioid analgesic. Int J Nanomedicine. 2016;11: 1475-1482.

2. Sinico C, Fadda AM. Vesicular carriers for dermal drug delivery. Expert Opin Drug Deliv. 2009;6(8):813-825.

3. Cevc G, Mazgareanu S, Rother M, Vierl U. Occlusion effect on transcutaneous NSAID delivery from conventional and carrier-based formulations. Int J Pharm. 2008;359(1-2):190-197.

4. Zheng WS, Fang XQ, Wang LL, Zhang YJ. Preparation and quality assessment of itraconazole transfersomes. Int J Pharm. 2012; 436(1-2):291-298.

5. Cevc G, Blume G. Lipid vesicles penetrate into intact skin owing to the transdermal osmotic gradients and hydration force. Biochim Biophys Acta. 1992;1104(1):226-232.

6. Benson HA. Transfersomes for transdermal drug delivery. Expert Opin Drug Deliv. 2006;3(6):727-737.

7. Chen J, Lu WL, Gu W, Lu SS, Chen ZP, Cai BC. Skin permeation behavior of elastic liposomes: role of formulation ingredients. Expert Opin Drug Deliv. 2013;10(6):845-856.

8. El Maghraby GM, Barry BW, Williams AC. Liposomes and skin: from drug delivery to model membranes. Eur J Pharm Sci. 2008; 34(4-5):203-222.

9. Geusens B, Lambert J, De Smedt SC, Buyens K, Sanders NN, Van Gele M. Ultradeformable cationic liposomes for delivery of smal interfering RNA (siRNA) into human primary melanocytes. $J$ Control Release. 2009;133(3):214-220.

10. Glenn GM, Scharton-Kersten T, Alving CR. Advances in vaccine delivery: transcutaneous immunisation. Expert Opin Investig Drugs. 1999;8(6):797-805.

11. Kang MJ, Eum JY, Park SH, et al. Pep-1 peptide-conjugated elastic liposomal formulation of taxifolin glycoside for the treatment of atopic dermatitis in NC/Nga mice. Int J Pharm. 2010;402(1-2):198-204.

12. Mishra D, Dubey V, Asthana A, Saraf DK, Jain NK. Elastic liposomes mediated transcutaneous immunization against hepatitis B. Vaccine 2006;24(22):4847-4855.

13. Mishra D, Garg M, Dubey V, Jain S, Jain NK. Elastic liposomes mediated transdermal delivery of an anti-hypertensive agent: propranolol hydrochloride. J Pharm Sci. 2007;96(1):145-155.

14. Lakshmi PK, Kalpana B, Prasanthi D. Invasomes-novel vesicular carriers for enhanced skin permeation. Syst Rev Pharm. 2013;4(1):26-30.
15. Hussain A, Samad A, Ramzan M, Ahsan MN, Ur Rehman Z, Ahmad FJ. Elastic liposome-based gel for topical delivery of 5-fluorouracil: in vitro and in vivo investigation. Drug Deliv. 2014;23(4):1115-1129.

16. Balaguer-Fernández C, Femenía-Font A, Merino V, et al. Elastic vesicles of sumatriptan succinate for transdermal administration: characterization and in vitro permeation studies. J Liposome Res. 2011; 21(1):55-59.

17. Ita KB, Du Preez J, Lane ME, Hadgraft J, du Plessis J. Dermal delivery of selected hydrophilic drugs from elastic liposomes: effect of phospholipid formulation and surfactants. J Pharm Pharmacol. 2007; 59(9):1215-1222.

18. Montanari J, Roncaglia DI, Lado LA, Morilla MJ, Romero EL. Avoiding failed reconstitution of ultradeformable liposomes upon dehydration. Int J Pharm. 2009;372(1-2):184-190.

19. El Maghraby GM, Williams AC, Barry BW. Skin delivery of oestradiol from lipid vesicles: importance of liposome structure. Int $J$ Pharm. 2000;204(1-2):159-169.

20. El Maghraby GM, Williams AC, Baryy BW. Interactions of surfactants (edge activators) and skin penetration enhancers with liposomes. Int $J$ Pharm. 2004;276(1-2):143-161.

21. López O, Cócera M, Wehrli E, Parra JL, de la Maza A. Solubilization of liposomes by sodium dodecyl sulfate: new mechanism based on the direct formation of mixed micelles. Arch Biochem Biophys. 1999; 367(2):153-160

22. Jain S, Jain P, Umamaheshwari RB, Jain NK. Transfersomes - a novel vesicular carrier for enhanced transdermal delivery: development, characterization, and performance evaluation. Drug Dev Ind Pharm. 2003; 29(9):1013-1026.

23. Mishra D, Mishra PK, Dubey V, Dabadghao S, Jain NK. Evaluation of uptake and generation of immune response by murine dendritic cells pulsed with hepatitis B surface antigen-loaded elastic liposomes. Vaccine. 2007;25(39-40):6939-6944.

24. Simões SI, Tapadas JM, Marques CM, Cruz ME, Martins MB, Cevc G. Permeabilisation and solubilisation of soybean phosphatidylcholine bilayer vesicles, as membrane models, by polysorbate, Tween 80 . Eur J Pharm Sci. 2005;26(3-4):307-317.

25. El-Zaafarany GM, Awad GA, Holayel SM, Mortada ND. Role of edge activators and surface charge in developing ultradeformable vesicles with enhanced skin delivery. Int J Pharm. 2010;397(1-2): 164-172.

26. Aggarwal N, Goindi S. Preparation and evaluation of antifungal efficacy of griseofulvin loaded deformable membrane vesicles in optimized guinea pig model of Microsporum canis - dermatophytosis. Int J Pharm. 2012;437(1-2):277-287.

27. Utreja P, Jain S, Tiwary AK. Localized delivery of paclitaxel using elastic liposomes: formulation development and evaluation. Drug Deliv. 2011;18(5):367-376.

28. Elsayed MM, Abdallah OY, Naggar VF, Khalafallah NM. Lipid vesicles for skin delivery of drugs: reviewing three decades of research. Int $J$ Pharm. 2007;332(1-2):1-16.

29. Christophers E, Kligman AM. Visualization of the cell layers of the stratum corneum. J Invest Dermatol. 1964;42:407-409.

30. Scheuplein RJ. Mechanisms of percutaneous absorption. II. Transient diffusion and the relative importance of various routes of skin penetration. J Invest Dermatol. 1967;48(1):79-88.

31. Abd E, Yousef SA, Pastore MN, et al. Skin models for the testing of transdermal drugs. Clin Pharmacol. 2016;8:163-176.

32. Perez AP, Altube MJ, Schilrreff P, et al. Topical amphotericin B in ultradeformable liposomes: formulation, skin penetration study, antifungal and antileishmanial activity in vitro. Colloids Surf B Biointerfaces. 2016;139:190-198.

33. Hadgraft J. Skin, the final frontier. Int J Pharm. 2001;224(1-2):1-18.

34. Hadgraft J. Modulation of the barrier function of the skin. Skin Pharmacol Appl Skin Physiol. 2001;14(Suppl 1):72-81.

35. Fang YP, Wong YT. Topical delivery of thymidine dinucleotide to induce p53 generation in the skin by elastic. Int J Biol Biomol Agri Food Biotechnol Eng. 2012;6(6):381-384. 
36. Hussain A, Haque MW, Singh SK, Ahmad FJ. Optimized permeation enhancer for topical delivery of 5-fluorouracil-loaded elastic liposome using Design Expert: part-II. Drug Deliv. 2016;23(4):1242-1253.

37. Utreja P, Jain S, Tiwary AK. Evaluation of biosafety and intracellular uptake of Cremophor EL free paclitaxel elastic liposomal formulation. Drug Deliv. 2012;19(1):11-20.

38. Severino P, Moraes LF, Zanchetta B, Souto EB, Santana MH. Elastic liposomes containing benzophenone-3 for sun protection factor enhancement. Pharm Dev Tech. 2012;17(6):661-665.

39. Wissing S, Lippacher A, Müller R. Investigations on the occlusive properties of solid lipid nanoparticles (SLN). J Cosmet Sci. 2001;52(5): 313-324.

40. Leung DY. Atopic dermatitis: the skin as a window into the pathogenesis of chronic allergic diseases. J Allergy Clin Immunol. 1995;96(3): 302-318.

41. Watanabe M, Tagami H, Horii I, Takahashi M, Kligman AM. Functional analyses of the superficial stratum corneum in atopic xerosis. Arch Dermatol. 1991;127(11):1689-1692.

42. Lee O, Choi M, Ha S, et al. Effect of pedunculagin investigated by non-invasive evaluation on atopic-like dermatitis in NC/Nga mice. Skin Res Technol. 2010;16(3):371-377.

43. Trotta M, Peira E, Debernardi F, Gallarate M. Elastic liposomes for skin delivery of dipotassium glycyrrhizinate. Int J Pharm. 2002;241(2): 319-327.

44. Kim ST, Lee KM, Park HJ, Jin SE, Ahn WS, Kim CK. Topical delivery of interleukin-13 antisense oligonucleotides with cationic elastic liposome for the treatment of atopic dermatitis. J Gene Med. 2009;11(1): 26-37.

45. Goindi S, Kumar G, Kumar N, Kaur A. Development of novel elastic vesicle-based topical formulation of cetirizine dihydrochloride for treatment of atopic dermatitis. AAPS PharmSciTech. 2013;14(4): $1284-1293$

46. Vanić Ž, Hafner A, Bego M, Škalko-Basnet N. Characterization of various deformable liposomes with metronidazole. Drug Dev Ind Pharm. 2013;39(3):481-488.

47. Ramos Lde S, Barbedo LS, Braga-Silva LA, dos Santos AL, Pinto MR, Sgarbi DB. Protease and phospholipase activities of Candida spp. isolated from cutaneous candidiasis. Rev Iberoam Micol. 2015;32(2): $122-125$.

48. Schram AM, Kim B, Carlos C, Tetzlaff MT, Schuster M, Rosenbach M. Primary cutaneous Candida tropicalis infection in a patient with B-cell lymphoma. Cutis. 2014;93(4):204-206.

49. de Araújo Pereira RR, Bruschi ML. Vaginal mucoadhesive drug delivery systems. Drug Dev Ind Pharm. 2012;38(6):643-652.

50. Pandit J, Garg M, Jain NK. Miconazole nitrate bearing ultraflexible liposomes for the treatment of fungal infection. J Liposome Res. 2014; 24(2):163-169.

51. Alomrani AH, Shazly GA, Amara AA, Badran MM. Itraconazolehydroxypropyl- $\beta$-cyclodextrin loaded deformable liposomes: in vitro skin penetration studies and antifungal efficacy using Candida albicans as model. Colloids Surf B Biointerfaces. 2014;121:74-81.

52. Hussain A, Samad A, Singh SK, et al. Nanoemulsion gel-based topical delivery of an antifungal drug: in vitro activity and in vivo evaluation. Drug Deliv. 2016;23(2):642-647.

53. Hussain A, Samad A, Nazish I, Ahmed FJ. Nanocarrier-based topical drug delivery for an antifungal drug. Drug Dev Ind Pharm. 2014; 40(4):527-541.

54. Nava D. Skin Aging Handbook: An Integrated Approach to Biochemistry and Product Development. Norwich, NY: William Andrew Inc.; 2008:213-215.

55. Tsai MJ, Huang YB, Fang JW, Fu YS, Wu PC. Preparation and characterization of naringenin-loaded elastic liposomes for topical application. PLoS One. 2015;10(7):e0131026.

56. de Gruijl FR. Photocarcinogenesis: UVA vs UVB radiation. Skin Pharmacol Appl Skin Physiol. 2002;15(5):316-320.

57. Tyrrell RM. Ultraviolet radiation and free radical damage to skin. Biochem Soc Symp. 1995;61:47-53.
58. Liu D, Hu H, Lin Z, et al. Quercetin deformable liposome: preparation and efficacy against ultraviolet $B$ induced skin damages in vitro and in vivo. J Photochem Photobiol B. 2013;127:8-17.

59. Saporito FC, Menter MA. Methotrexate and psoriasis in the era of new biologic agents. J Am Acad Dermatol. 2004;50(2):301-309.

60. Trotta M, Peira E, Carlotti ME, Gallarate M. Deformable liposomes for dermal administration of methotrexate. Int J Pharm. 2004;270(1-2): 119-125.

61. Bavarsad N, Akhgari A, Seifmanesh S, Salimi A, Rezaie A. Statistical optimization of tretinoin-loaded penetration-enhancer vesicles (PEV) for topical delivery. Daru. 2016;24:7.

62. Singh HP, Tiwary AK, Jain S. Preparation and in vitro, in vivo characterization of elastic liposomes encapsulating cyclodextrin-colchicine complexes for topical delivery of colchicine. Yakugaku Zasshi. 2010; 130(3):397-407.

63. Harris MD, Siegel LB, Alloway JA. Gout and hyperuricemia. Am Fam Physician. 1999;59(4):925-934.

64. Evans TI, Wheeler MT, Small RE, Breitbach SA, Sanders KM, Roberts WN. A comprehensive investigation of inpatient intravenous colchicine use shows more education is needed. JRheumatol. 1996;23(1): 143-148.

65. Singh HP, Utreja P, Tiwary AK, Jain S. Elastic liposomal formulation for sustained delivery of colchicine: in vitro characterization and in vivo evaluation of anti-gout activity. AAPS J. 2009;11(1):54-64.

66. Srisuk P, Thongnopnua P, Raktanonchai U, Kanokpanont S. Physicochemical characteristics of methotrexate-entrapped oleic acid-containing deformable liposomes for in vitro transepidermal delivery targeting psoriasis treatment. Int J Pharm. 2012;427(2):426-434.

67. Montanari J, Perez AP, Di Salvo F, et al. Photodynamic ultradeformable liposomes: design and characterization. Int J Pharm. 2007; 330(1-2):183-194.

68. Peira E, Trotta M, Carlotti ME, Gallarate M, Chirio D. Elastic positivelycharged liposomes for topical administration of acyclovir. J Drug Del Sci Tech. 2007;17(5):321-324.

69. Gillet A, Grammenos A, Compère P, Evrard B, Piel G. Development of a new topical system: drug-in-cyclodextrin-in-deformable liposome. Int J Pharm. 2009;380(1-2):174-180.

70. Maestrelli F, González-Rodríguez ML, Rabasco AM, Ghelardini C, Mura P. New "drug-in cyclodextrin-in deformable liposomes" formu lations to improve the therapeutic efficacy of local anesthetics. Int $J$ Pharm. 2010;395(1-2):222-231.

71. Cadena PG, Pereira MA, Cordeiro RB, et al. Nanoencapsulation of quercetin and resveratrol into elastic liposomes. Biochim Biophys Acta. 2013;1828(2):309-316.

72. Agrawal R, Sandhu SK, Sharma I, Kaur IP. Development and evaluation of curcumin-loaded elastic vesicles as an effective topical antiinflammatory formulation. AAPS PharmSciTech. 2015;16(2):364-374.

73. Desmet E, Bracke S, Forier K, et al. An elastic liposomal formulation for RNAi-based topical treatment of skin disorders: proof-of-concept in the treatment of psoriasis. Int J Pharm. 2016;500(1-2):268-274.

74. Jain S, Tiwary AK, Sapra B, Jain NK. Formulation and evaluation of ethosomes for transdermal delivery of lamivudine. AAPS PharmSciTech. 2007;8(4): E111.

75. Song YK, Kim CK. Topical delivery of low-molecular-weight heparin with surface-charged flexible liposomes. Biomaterials. 2006;27(2):271-280.

76. Dwivedi M, Sharma V, Pathak K. Pilosebaceous targeting by isotretenoin-loaded invasomal gel for the treatment of eosinophilic pustular folliculitis: optimization, efficacy and cellular analysis. Drug Dev Ind Pharm. 2017;43(2):293-304

77. Bos JD, Meinardi MM. The 500 Dalton rule for the skin penetration of chemical compounds and drugs. Exp Dermatol. 2000;9(3):165-169.

78. Qiu Y, Gao Y, Hu K, Li F. Enhancement of skin permeation of docetaxel: a novel approach combining microneedle and elastic liposomes. $J$ Control Release. 2008;129(2):144-150.

79. Al Sabbagh C, Tsapis N, Novell A, et al. Formulation and pharmacokinetics of thermosensitive stealth ${ }^{\circledR}$ liposomes encapsulating 5-fluorouracil. Pharm Res. 2015;32(5):1585-1603. 
80. Ahad A, Aqil M, Kohli K, Sultana Y, Mujeeb M, Ali A. Formulation and optimization of nanotransfersomes using experimental design technique for accentuated transdermal delivery of valsartan. Nanomedicine. 2012;8(2):237-249.

81. Manvir A, Rana AC, Seth N, Bala R. Elastic liposome mediated transdermal delivery of an anti-hypertensive agent: nifedipine. J Drug Delivy Therap. 2012;2(5):55-60.

82. Duangjit S, Opanasopit P, Rojanarata T, Ngawhirunpat T. Effect of edge activator on characteristic and in vitro skin permeation of meloxicam loaded in elastic liposomes. Adv Mat Res. 2011;194-196: 537-540.

83. Nava G, Piñón E, Mendoza L, Mendoza N, Quintanar D, Ganem A. Formulation and in vitro, ex vivo and in vivo evaluation of elastic liposomes for transdermal delivery of ketorolac tromethamine. Pharmaceutics. 2011;3(4):954-970.

84. Uchino T, Lefeber F, Gooris G, Bouwstra J. Physicochemical characterization of drug-loaded rigid and elastic vesicles. Int J Pharm. 2011 412(1-2):142-147.

85. Palac Z, Hurler J, Škalko-Basnet N, Filipović-Grčić J, Vanić Ž. Elastic liposomes-in-vehicle formulations destined for skin therapy: the synergy between type of liposomes and vehicle. Drug Dev Ind Pharm. 2015; 41(8):1247-1253.

86. Cereda CM, Franz-Montan M, da Silva CM, et al. Transdermal delivery of butamben using elastic and conventional liposomes. J Liposome Res. 2013;23(3):228-234

87. Li L, Zhang Y, Han S, et al. Penetration enhancement of lidocaine hydrochlorid by a novel chitosan coated elastic liposome for transdermal drug delivery. J Biomed Nanotechnol. 2011;7(5):704-713.

88. Essa EA, Bonner MC, Barry BW. Electroporation and ultradeformable liposomes; human skin barrier repair by phospholipid. $J$ Control Release. 2003;92(1-2):163-172.

89. Elsayed MM, Abdallah OY, Naggar VF, Khalafallah NM. Deformable liposomes and ethosomes: mechanism of enhanced skin delivery. Int J Pharm. 2006;322(1-2):60-66.

90. Li S, Qiu Y, Zhang S, Gao Y. Enhanced transdermal delivery of $18 \beta$ glycyrrhetic acid via elastic vesicles: in vitro and in vivo evaluation. Drug Dev Ind Pharm. 2012;38(7):855-865.

91. Maheshwari RG, Tekade RK, Sharma PA, et al. Ethosomes and ultradeformable liposomes for transdermal delivery of clotrimazole: a comparative assessment. Saudi Pharm J. 2012;20(2):161-170.

92. Hattori Y, Date M, Arai S, Kawano K, Yonemochi E, Maitani Y. Transdermal delivery of small interfering RNA with elastic cationic liposomes in mice. J Pharm (Cairo). 2013;2013:149695.

93. Kasetvatin C, Rujivipat S, Tiyaboonchai W. Combination of elastic liposomes and low frequency ultrasound for skin permeation enhancement of hyaluronic acid. Colloids Surf B Biointerfaces. 2015;135: 458-464.

94. Al Shuwaili AH, Rasool BK, Abdulrasool AA. Optimization of elastic transfersomes formulations for transdermal delivery of pentoxifylline. Eur J Pharm Biopharm. 2016;102:101-114.

95. Qadri GR, Ahad A, Aqil M, Imam SS, Ali A. Invasomes of isradipine for enhanced transdermal delivery against hypertension: formulation, characterization, and in vivo pharmacodynamic study. Artif Cells Nanomed Biotechnol. 2017;45(1):139-145.

96. Song YK, Hyun SY, Kim HT, Kim CK, Oh JM. Transdermal delivery of low molecular weight heparin loaded in flexible liposomes with bioavailability enhancement: comparison with ethosomes. J Microencapsul. 2011;28(3):151-158.

97. Duangjit S, Obata Y, Sano H, et al. Menthosomes, novel ultradeformable vesicles for transdermal drug delivery: optimization and characterization. Biol Pharm Bull. 2012;35(10):1720-1728.

98. Duangjit S, Nimcharoenwan T, Chomya N, Locharoenrat N, Ngawhirunpat T. Computational design strategy: an approach to enhancing the transdermal delivery of optimal capsaicin-loaded transinvasomes. Drug Dev Ind Pharm. 2017;43(1):98-107.

99. Illum $\mathrm{L}$. Transport of drugs from the nasal cavity to the central nervous system. Eur J Pharm Sci. 2000;11(1):1-18.
100. Thorne RG, Pronk GJ, Padmanabhan V, Frey WH 2nd. Delivery of insulin-like growth factor-I to the rat brain and spinal cord along olfactory and trigeminal pathways following intranasal administration. Neuroscience. 2004;127(2):481-496.

101. Garg T, Jain S, Singh HP, Sharma A, Tiwary AK. Elastic liposomal formulation for sustained delivery of antimigraine drug: in vitro characterization and biological evaluation. Drug Dev Ind Pharm. 2008; 34(10):1100-1110.

102. Villalón CM, Centurión D, Valdivia LF, de Vries P, Saxena PR. Migraine: pathophysiology, pharmacology, treatment and future trends. Curr Vasc Pharmacol. 2003;1(1):71-84.

103. Langtry HD, Clissold SP. Pergolide. A review of its pharmacological properties and therapeutic potential in Parkinson's disease. Drugs. 1990;39(3):491-506

104. Honeywell-Nguyen PL, Frederik PM, Bomans PH, Junginger HE, Bouwstra JA. Transdermal delivery of pergolide from surfactant-based elastic and rigid vesicles: characterization and in vitro transport studies. Pharm Res. 2002;19(7):991-997.

105. Glenn GM, Rao M, Matyas GR, Alving CR. Skin immunization made possible by cholera toxin. Nature. 1998;391(6670):851.

106. Foged C, Sundblad A, Hovgaard L. Targeting vaccines to dendritic cells. Pharm Res. 2002;19(3):229-238.

107. Ding Z, Bivas-Benita M, Hirschberg H, Kersten GF, Jiskoot W, Bouwstra JA. Preparation and characterization of diphtheria toxoidloaded elastic vesicles for transcutaneous immunization. J Drug Target. 2008;16(7):555-563.

108. Shi Z, Curiel DT, Tang DC. DNA-based non-invasive vaccination onto the skin. Vaccine. 1999;17(17):2136-2141.

109. Singh RP, Singh P, Mishra V, Prabakaran D, Vyas SP. Vesicular systems for non-invasive topical immunization: rationale and prospects. Ind J Pharmacol. 2002;34:301-310.

110. Gupta PN, Singh P, Mishra V, Jain S, Dubey PK, Vyas SP. Topical immunization: mechanistic insight and novel delivery systems. Ind $J$ Biotechnol. 2004;3:9-21.

111. Mishra D, Mishra PK, Dabadghao S, Dubey V, Nahar M, Jain NK. Comparative evaluation of hepatitis B surface antigen-loaded elastic liposomes and ethosomes for human dendritic cell uptake and immune response. Nanomedicine. 2010;6(1):110-118.

112. Tyagi RK, Garg NK, Jadon R, et al. Elastic liposome-mediated transdermal immunization enhanced the immunogenicity of P. falciparum surface antigen, MSP-119. Vaccine. 2015;33(36):4630-4638.

113. Glenn GM, Taylor DN, Li X, Frankel S, Montemarano A, Alving CR. Transcutaneous immunization: a human vaccine delivery strategy using a patch. Nat Med. 2000;6(12):1403-1406.

114. Matyas GR, Friedlander AM, Glenn GM, Little S, Yu J, Alving CR. Needle-free skin patch vaccination method for anthrax. Infect Immun. 2004;72(2):1181-1183.

115. Shahiwala A, Misra A. Preliminary investigation of the nasal delivery of liposomal leuprorelin acetate for contraception in rats. $J$ Pharm Pharmacol. 2006;58(1):19-26.

116. Smith J, Wood E, Dornish M. Effect of chitosan on epithelial cell tight junctions. Pharm Res. 2004;21(1):43-49.

117. Elhissi AM, Giebultowicz J, Stec AA, et al. Nebulization of ultradeformable liposomes: the influence of aerosolization mechanism and formulation excipients. Int J Pharm. 2012;436(1-2):519-526.

118. Li X, Chen D, Le C, et al. Novel mucus-penetrating liposomes as a potential oral drug delivery system: preparation, in vitro characterization, and enhanced cellular uptake. Int J Nanomedicine. 2011;6:3151-3162.

119. Hua S. Orally administered liposomal formulations for colon targeted drug delivery. Front Pharmacol. 2014;5:138.

120. Thanou M, Florea BI, Langemeÿer MW, Verhoef JC, Junginger HE. $\mathrm{N}$-trimethylated chitosan chloride (TMC) improves the intestinal permeation of the peptide drug buserelin in vitro (Caco-2 cells) and in vivo (rats). Pharm Res. 2000;17(1):27-31.

121. Huang YB, Tsai MJ, Wu PC, Tsai YH, Wu YH, Fang JY. Elastic liposomes as carriers for oral delivery and the brain distribution of (+)-catechin. J Drug Target. 2011;19(8):709-718. 


\section{Publish your work in this journal}

The International Journal of Nanomedicine is an international, peerreviewed journal focusing on the application of nanotechnology in diagnostics, therapeutics, and drug delivery systems throughout the biomedical field. This journal is indexed on PubMed Central,

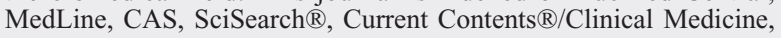

Journal Citation Reports/Science Edition, EMBase, Scopus and the Elsevier Bibliographic databases. The manuscript management system is completely online and includes a very quick and fair peer-review system, which is all easy to use. Visit http://www.dovepress.com/ testimonials.php to read real quotes from published authors.

Submit your manuscript here: http://www.dovepress.com/international-journal-of-nanomedicine-journal 